\title{
EVAPOTRANSPIRATION: A PROCESS DRIVING MASS TRANSPORT AND ENERGY EXCHANGE IN THE SOIL-PLANT-ATMOSPHERE-CLIMATE SYSTEM
}

\author{
Gabriel G. Katul, ${ }^{1,2,3}$ Ram Oren, ${ }^{1,2,4}$ Stefano Manzoni, ${ }^{1,2}$ Chad Higgins, ${ }^{5}$ \\ and Marc B. Parlange ${ }^{6}$ \\ Received 1 June 2011; revised 30 April 2012; accepted 4 May 2012; published 20 July 2012.
}

[1] The role of evapotranspiration (ET) in the global, continental, regional, and local water cycles is reviewed. Elevated atmospheric $\mathrm{CO}_{2}$, air temperature, vapor pressure deficit $(D)$, turbulent transport, radiative transfer, and reduced soil moisture all impact biotic and abiotic processes controlling ET that must be extrapolated to large scales. Suggesting a blueprint to achieve this link is the main compass of this review. Leaf-scale transpiration $\left(f_{e}\right)$ as governed by the plant biochemical demand for $\mathrm{CO}_{2}$ is first considered. When this biochemical demand is combined with mass transfer formulations, the problem remains mathematically intractable, requiring additional assumptions. A mathematical "closure" that assumes stomatal aperture is autonomously regulated so as to maximize the leaf carbon gain while minimizing water loss is proposed, which leads to analytical expressions for leaf-scale transpiration. This formulation predicts well the effects of elevated atmospheric $\mathrm{CO}_{2}$ and increases in $D$ on $f_{e}$. The case of soil moisture stress is then considered using extensive gas exchange measurements collected in drought studies. Upscaling the $f_{e}$ to the canopy is then discussed at multiple time scales. The impact of limited soil water availability within the rooting zone on the upscaled ET as well as some plant strategies to cope with prolonged soil moisture stress are briefly presented. Moving further up in direction and scale, the soil-plant system is then embedded within the atmospheric boundary layer, where the influence of soil moisture on rainfall is outlined. The review concludes by discussing outstanding challenges and how to tackle them by means of novel theoretical, numerical, and experimental approaches.

Citation: Katul, G. G., R. Oren, S. Manzoni, C. Higgins, and M. B. Parlange (2012), Evapotranspiration: A process driving mass transport and energy exchange in the soil-plant-atmosphere-climate system, Rev. Geophys., 50, RG3002, doi:10.1029/2011RG000366.

\footnotetext{
${ }^{1}$ Nicholas School of the Environment, Duke University, Durham, North Carolina, USA.

${ }^{2}$ Department of Civil and Environmental Engineering, Pratt School of Engineering, Duke University, Durham, North Carolina, USA.

${ }^{3}$ Dipartimento di Idraulica, Trasporti ed Infrastrutture Civili, Politecnico di Torino, Torino, Italy.

${ }^{4}$ Department of Forest Ecology and Management, Swedish University of Agricultural Sciences, Umeå, Sweden.

${ }^{5}$ Department of Biological and Ecological Engineering, Oregon State University, Corvallis, Oregon, USA.

${ }^{6}$ School of Architecture, Civil and Environmental Engineering, École Polytechnique Fédérale de Lausanne, Lausanne, Switzerland.

Corresponding author: G. G. Katul, Nicholas School of the Environment, Duke University, PO Box 90328, Durham, NC 27708-0328, USA. (gaby@duke.edu)
}

\section{INTRODUCTION}

\subsection{Definitions}

[2] Evaporation is a phase transition in which liquid molecules spontaneously become gaseous. Molecular vibration and collisions accelerate molecules adjacent to the gas-liquid interface, causing them to acquire enough kinetic energy to overcome intermolecular forces in the liquid and enter the gaseous phase. The mean kinetic energy of the molecules in the liquid phase is linearly proportional to the temperature via the Boltzmann constant so that evaporation is enhanced at higher liquid temperatures. As faster-moving molecules escape the water surface, the remaining molecules have a lower mean kinetic energy resulting in a bulk temperature decrease of the liquid. Water, with its relatively high intermolecular forces (but are much weaker than the intramolecular 


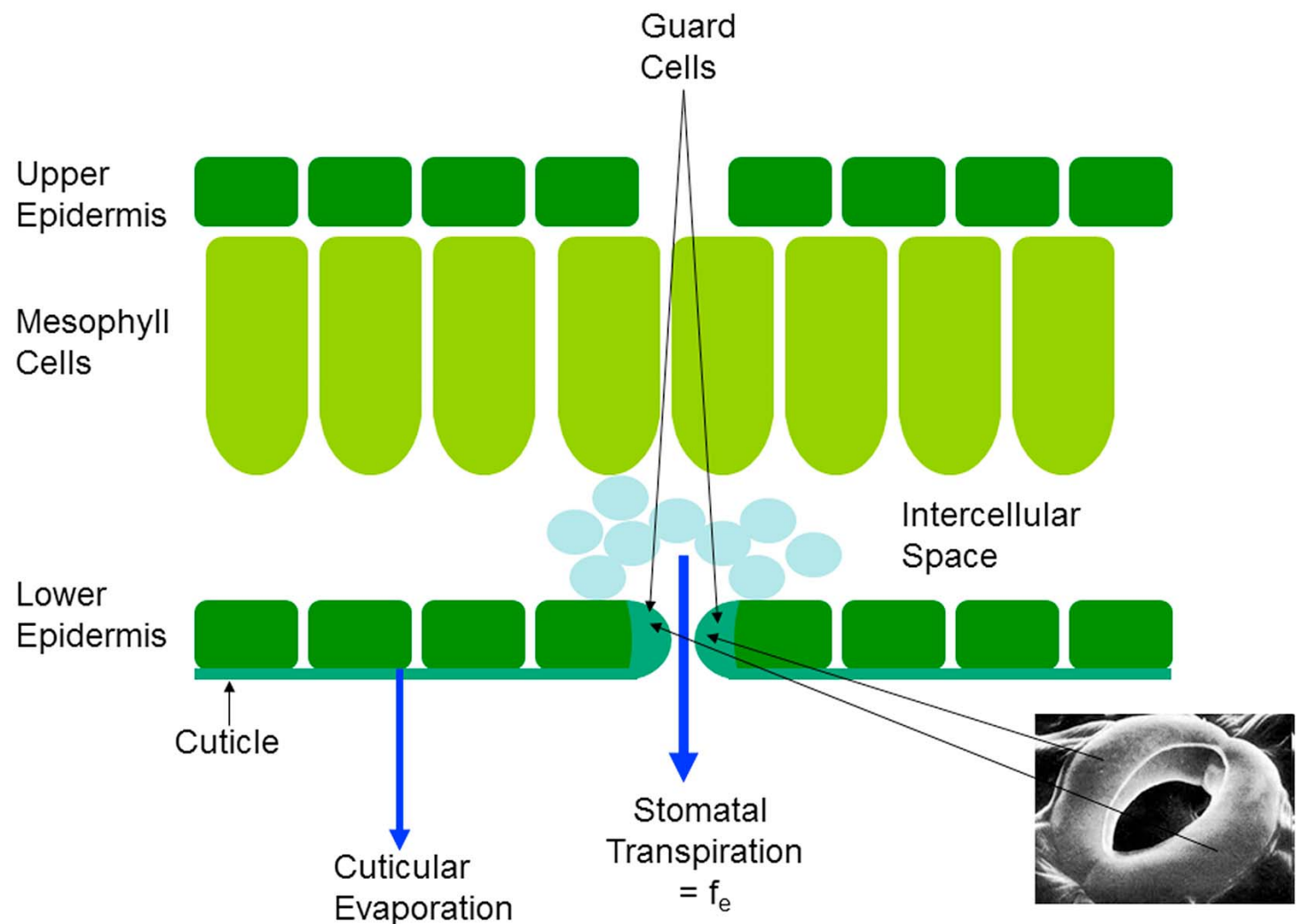

Figure 1. Flow of water from the leaf to the atmosphere. The guard cells regulate the stomatal aperture and hence the transpiration rate $\left(=f_{e}\right)$. The dual role of stomata as conduits for water vapor and $\mathrm{CO}_{2}$ ensures coupling of transpiration with carbon and energy dynamics.

forces) and thus a correspondingly large latent heat of vaporization, is particularly effective at generating such evaporative cooling. This evaporative cooling is then compensated for by heat transfer from the surrounding environment, and after some equilibration time, the mean kinetic energy of the liquid water molecules is increased thereby allowing evaporation to proceed until all the water molecules evaporate. Hence, evaporation requires an external source of energy to compensate for the evaporative cooling that is provided by the surrounding environment. The "molecular thermodynamic" theory of evaporation based on the Boltzmann (also known as Gibbs) distribution describing the speed of molecules provides a working model for evaporation and its associated link with internal energy, which has been used for over 270 years [Van Wylen and Sonntag, 1978], arguably since Daniel Bernoulli proposed the kinetic theory of gases to explain air pressure from a molecular perspective in the early 1700 s. It explains why, at the molecular level, increases in temperature or external energy enhance evaporation. It also provides some theoretical basis for many empirical models (e.g., the Blaney-Criddle formula) widely used in practice (e.g., the Food and Agricultural Organization of the United Nations) for computing evapotranspiration (ET) [Allen and Pruitt, 1986].

[3] The term evapotranspiration emphasizes the combined flux associated with two different pathways of water vaporization in environmental systems: (1) abiotic water evaporation from open water bodies (lakes, ocean, etc.), surface plant residues and soil pores, cuticle surfaces of leaves, and (2) biotic leaf transpiration (denoted here by $f_{e}$ ) in which vaporization occurs by the diffusion of water molecules from leaf chloroplasts to the atmosphere via the stomata (Figure 1). Guard cells can control the stomatal pore aperture and thus loss of water vapor from within the leaf to the atmosphere. This "active biological control" distinguishes leaf transpiration as a "biotic" process from the general "abiotic" physical mechanisms governing evaporation [van den Honert, 1948]. Because plants need to remain well hydrated to sustain their physiological activities [Hsiao, 1973], transpiration can be thought of as a "cost" or a "penalty" incurred by plants when they open their stomata to satisfy their photosynthetic demand for atmospheric carbon dioxide [Cowan and Farquhar, 1977; Givnish and Vermeij, 1976]. Yet, $f_{e}$ can be beneficial to plants because cooling the leaf may reduce respiration, thus increasing the net carbon gain during photosynthesis. This cooling may protect leaves from heat damage, thus protecting the investment in the photosynthetic machinery and ensuring continued function and replenishment of water loss from leaves by water taken from the soil that delivers mineral nutrients to plant organs.

[4] In terms of its importance in the hydrologic cycle, ET accounts for some $60 \%$ of terrestrial precipitation [Shiklomanov, 1998] and can approach 100\% of annual rainfall in water-limited ecosystems, with transpiration often 
a dominant term in many vegetated landscapes [Budyko, 1974]. Hence, how these biotic and abiotic mechanisms controlling ET will be altered in the future remains a central research problem for ecosystem services, water resources management, and climate change predictions.

\subsection{Review of Reviews}

[5] There is more than 400 years of research investigating the biotic and abiotic controls on ET, generating a voluminous body of work that lies beyond the scope of a single review. Reviews and syntheses summarizing the historical developments through much of the first half of the 20th century and concomitant key findings are presented elsewhere [Brutsaert, 1982]. Modern research on ET in Earth Sciences has focused on three areas requiring an expansion of the conventional molecular thermodynamic view: (1) transpiration as indicator of the plant stress status [Hsiao, 1973], (2) leaf transpiration rates and their relationship to water vapor concentration in the atmosphere [Monteith, 1995; Oren et al., 1999], and (3) ET as a process that drives mass transport and energy exchange, a perspective needed in climate science and atmospheric boundary layer (ABL) dynamics. This review will primarily focus on the latter category, although the biophysical basis of transpiration responses to environmental conditions will be considered [see also Jones, 1992; Cruiziat et al., 2002; Manzoni et al., 2012].

[6] Work on evaporation as a process driving mass transport commenced in the early 1800 s with Dalton and progressed as energy exchanges and evaporation were linked [Bowen, 1926; Penman, 1948]. Bowen [1926, abstract] was among the first to note that "the process of evaporation and diffusion of water vapor from any water surface into the body of air above it is exactly similar to that of conduction or diffusion of specific heat energy from the water surface into the same body of air." This realization later resulted in the so-called "combination equation" after Penman [1948]. Agricultural and ecological applications capitalized on these developments by including modifications to the original Penman equation to account for canopy stomatal resistance [Monteith, 1965]. These developments marked a shift in research emphasis from evaporation as a physically controlled process to evaporation as a process that must accommodate the physiological controls imposed by the stomatal guard cells [Darwin, 1898; Jarvis, 1976; Ziemer, 1979]. Concurrently, the potential sensitivity of the climate system to land surface processes in general and ET in particular was receiving significant attention following Manabe's seminal work [Manabe et al., 1965]. This likely sensitivity motivated a three-decadelong stretch during which "large-scale" field experiments (e.g., HAPEX-MOBILHY, HAPEX-SAHEL, FIFE, BOREAS, LBA, among others) were conducted to explore how spatial variations in ET should be accommodated in climate models [Andre et al., 1986; Avissar et al., 2002; Goutorbe et al., 1994; Sellers et al., 1992, 1997]. The rapid advances of this research, owed in part to the development and use of turbulent transport theories to explain how the atmosphere "senses" ET, are summarized in a number of reviews [Parlange et al., 1995].

\subsection{Scope}

[7] Building on this body of knowledge, this contribution synthesizes how observed changes in the global hydrologic cycle can be attributed to the responses of ET to varying environmental conditions at different spatial and temporal scales. Section 2 frames the problem at the global scale, offering a zeroth-order yet mechanistic interpretation of the changes in rainfall that have been observed in the last decades and that are predicted to occur in response to increased air temperature under future climatic conditions. However, disentangling different controls and drivers of ET in terrestrial systems remains particularly complicated. It is evident that elevated atmospheric $\mathrm{CO}_{2}$, air temperature, vapor pressure deficit $(D)$, turbulent transport, radiative transfer, and reduced soil moisture all impact biotic and abiotic processes controlling ET at the leaf-to-canopy scales, which must be extrapolated to even larger scales for regional-, continental-, and global-scale predictions. Section 3 addresses these issues at the leaf level, employing an optimization framework to parsimoniously link water and carbon economies at the leaf scale and predict transpiration responses to environmental drivers without resolving the details of chemical and mechanical controls regulating guard cell movement. Upscaling these leaf-scale processes to the canopy is then discussed at short and long time scales in sections 4 and 5, where the impact of limited soil water availability within the rooting zone on the upscaled ET as well as some plant strategies to cope with prolonged soil moisture stress are briefly presented. Moving further up in scale, the soil-plant system is embedded within the ABL, where the influence of soil moisture on rainfall is outlined (section 6). The review concludes by discussing outstanding challenges and suggests novel theoretical and experimental approaches to tackle them.

\section{SENSITIVITY OF THE WATER CYCLE TO CLIMATIC CHANGES}

\subsection{ET and the Global Water Cycle}

[8] The Earth's water is continuously in motion, and the terms "water cycle" or "hydrological cycle" describe the continuous movement of water molecules below, on, and above the surface of the Earth. The focus here is on alterations to the global hydrological cycle due to increases in anthropogenic emissions of greenhouse gases. Such global alterations are anticipated to not only impact the management of water resources at national and international levels [Huntington, 2006, 2010; Oki and Kanae, 2006] but also represent significant and uncertain feedbacks to the global climate system itself. Given the primary role of ET in the global hydrologic cycle [Shiklomanov, 1998], links between the biotic and abiotic processes driving ET must be forged. These links are essential for interpreting long-term hydrologic and climate records and for predicting the hydrologic cycle under elevated atmospheric $\mathrm{CO}_{2}$ and warmer air temperatures $\left(T_{a}\right)$. 


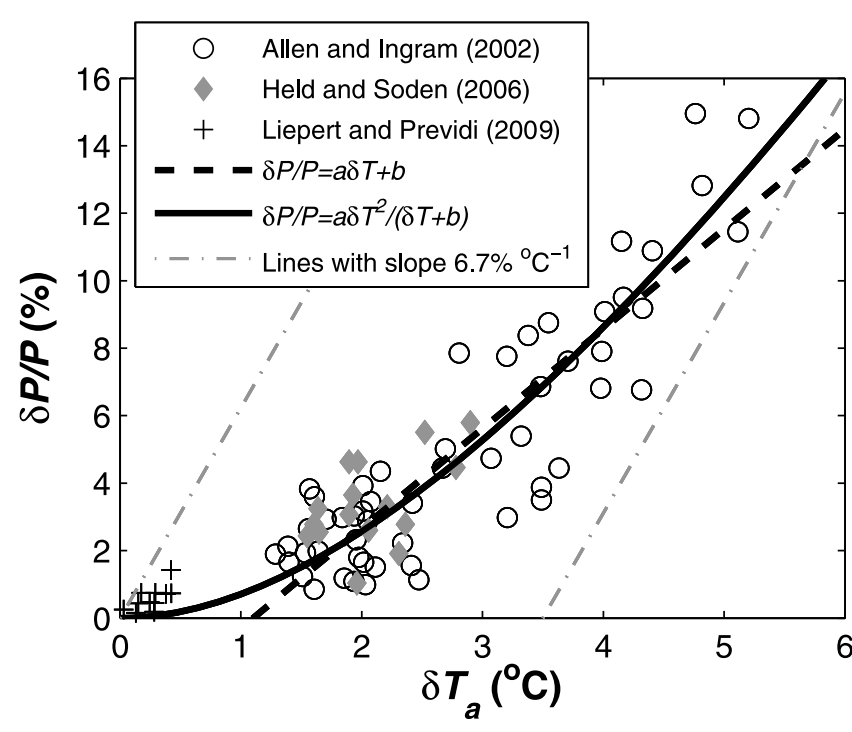

Figure 2. The acceleration of the hydrologic cycle as indicated by increases in $\delta P / P$ due to increases in temperature $\left(\delta T_{a}\right)$. The model runs for 1987-2006 climate reported by Liepert and Previdi [2009] are shown as crosses, the open circles are climate model runs reported by AI02 [Allen and Ingram, 2002] for future climate scenarios, the closed diamonds are climate model runs reported by Held and Soden [2006], the dashed line is the regression fit given as $\delta P / P=$ $2.95\left(\delta T_{a}-1.08\right)$ for climate model runs in AI02, and the dot-dashed lines are the slope prediction from the ClausiusClapeyron (CC) equation $\left(6.7 \%{ }^{\circ} \mathrm{C}^{-1}\right.$; see equation (6)). The solid black curve is the nonlinear regression fit to all the model runs and satellite observations reported here, given as $\delta P / P=6.7 \delta T_{a} /\left(8.46+\delta T_{a}\right)$. Note that when $\delta T_{a} \gg 8.5^{\circ} \mathrm{C}$, the CC slope is recovered.

[9] It is now accepted that increases in greenhouse gas emissions lead to increases in global air temperature $\left(=\delta T_{a}\right)$. However, the consequences of a global temperature increase $\delta T_{a}$ on the hydrological cycle are more difficult to predict [Dai et al., 1999; Dirmeyer and Brubaker, 2006; Trenberth et al., 2007]. At the global spatial scale and in the long term (e.g., decades or longer), the global hydrologic balance simplifies to $P \approx \mathrm{ET}$, where $P$ is the global precipitation and ET here includes evaporation and transpiration from land and ocean evaporation. Any perturbation to the global hydrologic cycle arising from $\delta T_{a}$ must affect both hydrologic fluxes so that

$$
\frac{\delta P}{P}=\frac{\delta \mathrm{ET}}{\mathrm{ET}}
$$

where $\delta P$ and $\delta \mathrm{ET}$ are perturbations in the global rainfall and global ET due to $\delta T_{a}$. Using Dalton's equation,

$$
\mathrm{ET} \approx g_{w} D
$$

where $g_{w}$ is interpreted as the "global conductance" or transfer coefficient of the surface (including ocean and land) to water vapor, and $D$ is an average global vapor pressure deficit defined as $e^{*}\left(T_{a}\right)(1-\mathrm{RH})$, where $e^{*}$ is the saturation vapor pressure at $T_{a}$ and $\mathrm{RH}$ is the global air relative humidity. From the Clausius-Clapeyron equation (hereafter referred to as $\mathrm{CC}$ ), $e^{*}$ can be related to $T_{a}$ using the so-called August-Roche-Magnus formula [Lawrence, 2005],

$$
e^{*}\left(T_{a}\right)=a_{c c} \exp \left(\frac{b T_{a}}{T_{a}+c}\right)
$$

where $T_{a}$ is in ${ }^{\circ} \mathrm{C}, a_{c c}=0.611 \mathrm{kPa}, b=17.5^{\circ} \mathrm{C}^{-1}$, and $c=$ $249.93^{\circ} \mathrm{C}$ for typical atmospheric pressures [Campbell and Norman, 1998]. In existing climate simulations, increased greenhouse gases result in $\delta T_{a}>0$ but do not lead to appreciable changes in $\mathrm{RH}$ across a wide range of climate scenarios [Allen and Ingram, 2002; Held and Soden, 2006; Sherwood and Meyer, 2006; Vecchi et al., 2006]. The nearconstant $\mathrm{RH}$ at the global scale is due to the fact that any increase in $P$ and ET is accompanied by increases in water vapor concentration, which in turn increases the actual vapor pressure. The ratio of the actual to saturation vapor pressure (or $\mathrm{RH}$ ) is less sensitive to increased $T_{a}$. Hence, to a first order, assuming (1) $\mathrm{RH}$ is insensitive to $\delta T_{a}$ and (2) $g_{w}$ remains unaltered from its present state, the perturbations in the hydrologic cycle reduce to [Katul and Novick, 2009]

$$
\begin{aligned}
\frac{\delta P}{P}=\frac{\delta D}{D}=\frac{\delta e^{*}\left(T_{a}\right)}{e^{*}\left(T_{a}\right)} & =\delta T_{a}\left[\frac{-b T_{a}}{\left(c+T_{a}\right)^{2}}+\frac{b}{c+T_{a}}\right] \\
& =\delta T_{a} \frac{b}{c+T_{a}}\left[\frac{-T_{a}}{\left(c+T_{a}\right)}+1\right] .
\end{aligned}
$$

Noting that $\left|-T_{a} /\left(c+T_{a}\right)\right| \ll 1$ results in

$$
\frac{\delta P}{P}=\frac{b}{c+T_{a}} \delta T_{a}
$$

Using a global mean air temperature $T_{a}=15^{\circ} \mathrm{C}$, and substituting the values of $b$ and $c$ leads to

$$
\frac{\delta P}{P}=\frac{\delta \mathrm{ET}}{\mathrm{ET}} \approx 0.0675 \delta T_{a},
$$

where $\delta P$ and $\delta \mathrm{ET}$ are projected changes in global precipitation and ET in response to $\delta T_{a}$, respectively [Allen and Ingram, 2002; Held and Soden, 2006]. Stated differently, this $\mathrm{CC}$ result suggests that the total amount of water vapor in the atmosphere will increase by about $6.8 \%{ }^{\circ} \mathrm{C}^{-1}$ warming of air temperature, and if all this excess water can be "converted" to $P$ as in equation (1), the global hydrological cycle should accelerate by about $6.8 \%{ }^{\circ} \mathrm{C}^{-1}$ warming. This finding motivates three broad questions: (1) To what extent do climate model projections agree with a $6.8 \%{ }^{\circ} \mathrm{C}^{-1}$ warming?, (2) Is there evidence of such large increases in $\delta P / P$ from the two decades of satellite observations of global rainfall and surface temperature now available?, and (3) What are the implications of an accelerating hydrologic cycle on global water resources over land (e.g., continental scales)? The tools available to investigate these "large-scale" questions include climate modeling and analyses of global satellite observations. 
[10] Analyses of satellite observations offer a range of interpretations of the sensitivity of $\delta P / P$ to $\delta T_{a}$ (Figure 2). Observations of the 1987-2006 period suggest that both $P$ and atmospheric water vapor concentration increased at about $7 \%{ }^{\circ} \mathrm{C}^{-1}$, assuming an air temperature increase of $0.2^{\circ} \mathrm{C}$ per decade in the lower troposphere [Wentz et al., 2007]. However, reexamination of the same satellite record seem to suggest that the rate of increase in $\delta P / P$ was more muted, closer to $2-3 \%{ }^{\circ} \mathrm{C}^{-1}$ [Liepert and Previdi, 2009]. Various climate model runs are summarized and presented in Figure 2 with predictions from the $\mathrm{CC}$ equation shown for comparison. It appears from Figure 2 that a minimum $\delta T_{a}=$ $1.08^{\circ} \mathrm{C}$ warming is needed for the modeled global precipitation to respond to increases in air temperature. This threshold presumably reflects the large "thermal inertia" of oceans. Beyond this threshold, the climate models predict an increase in $\delta P / P($ or $\delta \mathrm{ET} / \mathrm{ET})$ of about $3 \%{ }^{\circ} \mathrm{C}^{-1}$ of warming, which is $50 \%$ of the CC-based predictions. This result is similar to separate model runs over the 1979-2006 period that also show an increase in $\delta P / P$ of $2.3 \%{ }^{\circ} \mathrm{C}^{-1}$ [Adler et al., 2008]. Rainfall predictions for a shorter period (1987-2006) suggest an even smaller response of only $1.9 \%{ }^{\circ} \mathrm{C}^{-1}$ [Liepert and Previdi, 2009]. This lower response matches extrapolations of more recent climate model runs for various future climate scenarios reported elsewhere [Held and Soden, 2006]. However, when merging all data sets and fitting a nonlinear model of $\delta P / P$ as a function of $\delta T_{a}$, a single relationship emerges (solid line in Figure 2), showing increasing sensitivity of $\delta P / P$ as temperature increases, up to the theoretical limit of about $7 \%{ }^{\circ} \mathrm{C}^{-1}$ set by CC. As mentioned before, climate models tend to maintain a near-constant global tropospheric RH with increasing $\delta T_{a}$. Additionally, their predicted column-integrated water vapor concentrations closely follow CC predictions, at least when forced with measured sea surface temperatures. Hence, the fact that $\delta P$ or $\delta$ ET do not follow CC scaling suggests that other embedded limitations (e.g., $g_{w}$ ) on the hydrologic cycle are exacerbated by increasing $\delta T_{a}$ in climate models.

[11] Exploring the genesis of these limitations in such a simplified "zeroth-dimensional" framework is difficult. However, some hypotheses about the nature of these reductions can be introduced into the original global hydrologic balance by recalling that

$$
\frac{\delta P}{P}=\frac{\delta\left(g_{w} D\right)}{g_{w} D}=\frac{\delta D}{D}+\frac{\delta g_{w}}{g_{w}}=\frac{\delta e^{*}\left(T_{a}\right)}{e^{*}\left(T_{a}\right)}+\frac{\delta g_{w}}{g_{w}} .
$$

Noting that $\delta e^{*} / e^{*}$ follows $\mathrm{CC}$ (by definition) and that the model results in Figure 2 suggest a small response of $\delta P / P$ to increasing $\delta T_{a}$ when compared to CC leads to

$$
\frac{\delta P}{P}-\frac{\delta e^{*}\left(T_{a}\right)}{e^{*}\left(T_{a}\right)}=\frac{\delta g_{w}}{g_{w}}<0 .
$$

Using the linear scaling between $\delta P / P$ and $\delta T_{a}$ in Figure 2 for the various climate models along with the $\mathrm{CC}$ scaling for $\delta e^{*} / e^{*}$ leads to a simplified description of $\delta g_{w} / g_{w} \approx-\alpha$ $\delta e^{*} / e^{*}$, where $\alpha$ is a constant, positive parameter empirically describing the inhibiting effects of changes in $e^{*}$ on $g_{w}$. A finite $\alpha$ may be attributed to increased "inefficiencies" in the global hydrologic cycle in warmer climate (e.g., cloud cover and reductions in net radiative fluxes at the ocean surface) as well as to other constraints on precipitation beyond moisture availability. Thus, $\delta P / P=(1-\alpha) \delta e^{*} / e^{*}=$ $(1-\alpha)\left(0.065 \delta T_{a}\right)$. The model runs in Figure 2 suggest that $\alpha$ may be on the order of 0.5 , though at high $\delta T_{a}, \alpha$ approaches unity.

[12] An alternative way to interpret the observed sensitivity of rainfall to air temperature changes can be framed by using an elementary representation of $P$ as $M\left(\mathrm{RH} e^{*}\right)$, where $M$ can be viewed as the mass of water vapor exchanged between the boundary layer and the free troposphere per unit time. For such a representation,

$$
\frac{\delta P}{P}=\frac{\delta e^{*}}{e^{*}}+\frac{\delta M}{M},
$$

which results in $\delta M / M=\delta g_{w} / g_{w}<0$ for the climate models in Figure 2. This implies that the global mean mass flux in the precipitating convective eddies (primarily situated in tropical regions) must decrease with increasing $\delta T_{a}$, a result that has been noted in several climate models [Held and Soden, 2006]. In essence, equation (9) suggests that $\delta P / P \approx$ $\delta$ ET/ET can be decomposed into two components: a thermodynamic component $\left(\delta e^{*} / e^{*}\right)$ that is enhanced with increasing $\delta T_{a}$ at a rate commensurate with the $\mathrm{CC}$ and a dynamic component $(\delta M / M)$ regulating mass exchange between the boundary layer and the free troposphere that appears to be reduced with increasing $\delta T_{a}$. The causes of these reductions in $\delta M / M$ and their implications for a reduced global water vapor circulation remains a subject of research attention [Held and Soden, 2006].

\subsection{ET and the Terrestrial Water Cycle}

[13] Although continental-scale ET may be an order of magnitude smaller than oceanic evaporation, replenishment of most water resources and ecosystem goods and services, as well as delivery of essential nutrients to marine estuaries, depends on the balance between $P$ and ET, the terrestrial runoff $\left(R_{o}\right)$. Not only are the processes governing $g_{w}$ of terrestrial surfaces far more complex than in oceanic environments, but terrestrial environments support large-scale structured heterogeneities in the land surface (such as land use patterns or topographic variation), which complicate the interplay between $P$ and ET as discussed later in this review. Over extended periods of time, the global hydrologic balance over land can be expressed as

$$
R_{o} \approx P-\mathrm{ET}=P-g_{w, L} D,
$$

where $g_{w, L}$ is now the bulk conductance to water vapor flow estimated for terrestrial areas.

[14] Fluctuations in terrestrial ET directly impact $R_{o}$ and play a central role in linking climatic variability to the recharge of freshwater resources. Not surprisingly then, this link has been the subject of some 60 years of research [Gleick, 1989]. The approaches followed now are rooted in 
TABLE 1. Observed Global Changes in Solar Radiation ${ }^{\mathrm{a}}$

\begin{tabular}{ccc}
\hline $\begin{array}{c}\text { Measurement } \\
\text { Period }\end{array}$ & $\begin{array}{c}\text { Observed Change } \\
\text { in Radiation } \\
\left(\mathrm{W} \mathrm{m}^{-2} \mathrm{yr}^{-1}\right)\end{array}$ & \multicolumn{1}{c}{ Reference } \\
\hline $1958-1992$ & -0.51 & Stanhill and Cohen $[2001]$ \\
$1964-1980$ & -0.41 in densely & Alpert et al. [2005] \\
& populated areas & \\
& -0.16 in sparsely & \\
& populated areas & Pinker et al. [2005] \\
$1984-2001$ & +0.24 & Wild et al. $[2005] ;$ Wild [2009] \\
$1992-2002$ & +0.66 &
\end{tabular}

${ }^{\mathrm{a}}$ Katul and Novick [2009].

the pioneering work of Langbein, who was among the first to connect climatic fluctuations to runoff fluctuations via ET [Hoyt and Langbein, 1939; Langbein, 1949]. Large increases in $R_{o}$ have been reported for the period spanning 19011999 [Labat et al., 2004; Manabe et al., 2004a, 2004b; Milly et al., 2005; Peterson et al., 2002; Piao et al., 2007]. These increases appear greater than the modeled increases in terrestrial $P$. Climate models suggest a small positive trend in terrestrial precipitation $(\sim 1 \%)$ during the twentieth century [Hulme et al., 1998], but this is too small to explain the observed increases in $R_{o}$. Alternative explanations, including potential changes in ET, therefore merit investigation.

[15] Although nearly all studies investigating trends in terrestrial ET over the past 50-100 years suggest some change in this quantity has occurred, the direction of the change is not consistent among these studies. Nevertheless, three hypotheses have been promoted as "plausible" explanations for a decreasing ET over the past 50-100 years over land, each with its own limitations as discussed later: (1) a reduction in solar irradiance (or solar dimming) and thus available energy and bulk conductance, (2) an increase in atmospheric $\mathrm{CO}_{2}$ and thus a decrease in bulk conductance due to stomatal downregulation, and (3) land use changes (e.g., deforestation) reducing bulk conductance.

[16] The so-called "solar dimming" hypothesis [Ramanathan et al., 2001] argues that a reduction in solar irradiance has occurred due to increased cloud cover and/or aerosol concentrations, the latter being consistent with measured increases in air pollution throughout the past 100 years (see studies listed in Table 1). Solar irradiance provides much of the available energy to drive ET and influences bulk conductance through the effect of light on leaf photosynthesis (described later). A solar dimming of $2-4 \%$ per decade was reported for the period between 1960 and the late 1980s using the Baseline Surface Radiation Network of the World Climate Research Program. However, this solar dimming now appears to be giving way to solar "brightening" at a rate of about $1.6 \%$ per decade (see Table 1). The brightening is partly explained by the decline in Eastern European aerosol emissions along with tighter air quality regulations and by the recovery from the large aerosol loadings associated with the 1991 Pinatubo eruption. To what extend such dimming and brightening impact terrestrial ET remains a subject of research. Several authors have questioned this "continental" view of dimming, reporting that "dimming" was four times more frequently observed near population centers (defined as centers with a population size exceeding 0.1 million) than sparsely populated areas [Alpert et al., 2005].

[17] Pan evaporation records, often used as surrogates for potential ET, are among the longest available hydrologic records, spanning some 100 years in several locations and thus may offer clues on fluctuations in terrestrial ET. A decrease in pan evaporation rate was measured over the last 50 years over much of the conterminous U.S. and Russia; these trends were assumed to represent similar reductions in terrestrial ET [Peterson et al., 1995]. And yet increases in global precipitation and cloudiness over the conterminous U.S. were also reported [Dai et al., 1997; Karl et al., 1996; Karl and Knight, 1998]. These increases seem paradoxical when contrasted with reductions in ET deduced from the negative trends in pan evaporation measurements [Peterson et al., 1995]. Beyond the U.S. and Europe, there are also reports of decreasing pan evaporation in India, Venezuela, China, Australia, and Thailand, but positive trends were observed in other parts of the world [Brutsaert, 2006]. Evaporation measured from a pan can only be used as an approximate indicator of evaporation from the regional environment via a "crop coefficient," which assumes an ample supply of surface moisture. Indeed, based on the "complementary hypothesis," a hypothesis that argues that the sum of actual and potential ET is conserved in a region for a fixed available energy level, decreasing pan evaporation may actually be an indication of increasing terrestrial ET [Brutsaert and Parlange, 1998]. Unlike a crop coefficient formulation, the complementary hypothesis predicts that increased aridity in the atmosphere at a given net radiation level must be accompanied by low actual ET and high potential ET as reflected by pan evaporation (linked to high vapor pressure deficit).

[18] The complementary hypothesis between actual and potential evaporation in general [Brutsaert and Stricker, 1979; Granger, 1989; Morton, 1983; Parlange and Katul, 1992] and between pan evaporation and ET in particular has received support from a number of studies [Golubev et al., 2001; Hobbins et al., 2004; Kahler and Brutsaert, 2006; Lawrimore and Peterson, 2000; Walter et al., 2004]. However, a series of papers has argued that decreasing pan evaporation must be caused by global dimming as supported by additional evidence of decreasing landscape evaporation [Liu et al., 2004; Ohmura and Wild, 2002; Roderick and Farquhar, 2002]. Brutsaert [2006] showed these factors (global dimming and the complementary principle) are not mutually incompatible and that the observed decreases in pan evaporation are generally due to increased terrestrial evaporation consistent with independent local water balance calculations. Others show that pan evaporation may have declined due to measured decline in near-surface wind speeds [Groisman et al., 2004; Pryor et al., 2009; Roderick et al., 2007], a phenomenon labeled as "stilling." Pan evaporation is sensitive to fluctuations in mean wind speed, which is known to be influenced by numerous effects such as increased urbanization through increased surface roughness (especially around airports and expanding metropolitan areas). Hence, linking pan evaporation to actual ET depends on 
climatic regimes and perhaps local conditions. If the reduction in pan evaporation is taken along with the complementary relationship, increases of $R_{o}$ cannot be attributed to reductions in ET, necessitating further research into other causes (such as deep groundwater pumping producing surface runoff or accelerated glacial and snowmelt in some regions).

[19] The second hypothesis for explaining increases in $R_{o}$, promoted by sensitivity studies conducted using climate models, was aimed at exploring why $R_{o}$ dramatically increased in the past 50-100 years despite the increased freshwater usage. This hypothesis argues that a reduction in stomatal conductance should occur following the $100 \mathrm{ppm}$ increase in global atmospheric $\mathrm{CO}_{2}$ concentration over the past 100 years. The response of plant stomata to elevated atmospheric $\mathrm{CO}_{2}$ has been studied for more than 100 years now [Darwin, 1898] with some experiments supporting a decrease of up to $50 \%$ with doubling of atmospheric $\mathrm{CO}_{2}$ [Field et al., 1995; Ainsworth and Rogers, 2007]. When such stomatal conductance reduction functions were directly incorporated into land surface models embedded within the larger climate models, ET significantly declined and global runoff increased to levels apparently consistent with the observed $R_{o}$ trends [Betts et al., 2007; Gedney et al., 2006]. These climate models are now routinely employed as "Earth Simulators" for addressing potential $\mathrm{CO}_{2}$ induced interactions between terrestrial ecosystems and climate. This possible pathway between increased atmospheric $\mathrm{CO}_{2}$, reduced $g_{w, L}$, and increased $R_{o}$ is not new [Idso and Brazel, 1984]. However, significant reductions in conductance due to elevated atmospheric $\mathrm{CO}_{2}$ are not entirely supported by results from Free Air $\mathrm{CO}_{2}$ Enrichment (FACE) experiments. FACE experiments are designed to investigate how elevated atmospheric $\mathrm{CO}_{2}$ affects both leaf and whole-ecosystem biosphere-atmosphere exchange rates, and several studies investigated the relationship between leaf stomatal characteristics and elevated atmospheric $\mathrm{CO}_{2}$. In particular, these studies examined the phenotypic response of stomatal density (SD) and stomatal aperture (AP) to rising atmospheric $\mathrm{CO}_{2}$ in 15 species after 4 years exposure to a field $\mathrm{CO}_{2}$ gradient (200 to $550 \mathrm{ppm}$ ) or within three FACE sites [Reid et al., 2003]. Along the $\mathrm{CO}_{2}$ gradient experiments, SD showed no evidence of a decline due to increasing $\mathrm{CO}_{2}$, while AP decreased slightly [Reid et al., 2003]. It appears that without evolutionary changes, SD may not respond to atmospheric $\mathrm{CO}_{2}$ in the field and are unlikely to decrease in future climates characterized by high $\mathrm{CO}_{2}$. Results from the FACE studies at Duke Forest situated in a maturing Loblolly pine stand near Durham, North Carolina, also report no significant change in both leaf stomatal conductance and canopy-scale transpiration [Ellsworth et al., 1995; Pataki et al., 1998; Schäfer et al., 2002]. Results from a FACE experiment in a broadleaf deciduous canopy situated in the southeastern U.S. showed large reductions $(\sim 40 \%)$ in leaf stomatal conductance under elevated atmospheric $\mathrm{CO}_{2}$, but canopy-scale conductance was reduced by only about 10\% [Wullschleger and Norby, 2001; Wullschleger et al., 2002]. This discrepancy highlights the need to correctly upscale leaf level processes to the canopy by taking into account changes in leaf area and the canopy microenvironment, a topic also covered later in the review.

[20] The third hypothesis argues that the decrease in continental-scale ET over the past 100 years is related to large-scale land use changes, with deforestation being the "dominant" trend [Jackson et al., 2005; Piao et al., 2007]. Clearing forests for development or agricultural purposes decreases ET and thus contributes to increases in surface runoff [Jackson et al., 2005]. However, recent studies in arid basins suggest that this finding may not be a general result for water limited environments [Wilcox and Huang, 2010]. Direct experimental evidence of the impact of land cover conversion on ET is provided using long-term eddy covariance ET measurements carried out at the Duke Forest in three stands experiencing similar climatic and edaphic conditions [Stoy et al., 2006]. The measured difference between $P$ (the same for all three sites) and ET is smallest for a pine plantation, followed by the second-growth mixed hardwood forest, followed by an abandoned agricultural field (OF) that is harvested at least once annually to prevent woody encroachment. Hence, when climatic and edaphic conditions are similar, forested ecosystems, especially evergreen forests, tend to consume more water when compared to agricultural fields. Interestingly, the maximum difference of the quantity $P$-ET between OF and the forests was $180 \mathrm{~mm} \mathrm{y}^{-1}$ over a 5 year period, comparable to the globally averaged decrease in streamflow following the afforestation of grasslands, shrublands, or croplands $\left(227 \mathrm{~mm} \mathrm{y}^{-1}\right.$ globally, or ca. $38 \%$ on average) [Jackson et al., 2005]. Hence, deforestation can increase $R_{o}$ by some $20 \%$, if all other conditions remain the same (the impact of deforestation on $\delta P / P$ will be discussed later). Similar ET measurements are proliferating across a wide range of climatic conditions and biomes through FLUXNET, a global network of eddy covariance towers [Baldocchi et al., 2001]. Interpolated FLUXNET records suggest some increases of ET from 1982 to 1997 followed by no increases from 1998 to 2008 due to soil moisture limitations [Jung et al., 2010]. However, the interpretation of the ET series derived from the FLUXNET record is not without its own challenges, given that equating a turbulent water vapor flux measured from towers above a canopy to ET requires stationary and planar homogeneous atmospheric flow conditions without subsidence. These idealizations are acceptable only over homogeneous landscapes and ecosystems situated on horizontal terrains, thus avoiding biases in ET inferred from eddy covariance measurements.

[21] Additional contributions to changes in $g_{w, L}$ may become significant in the near future as air temperature and vapor pressure deficit continue to rise. For example, in addition to responses to increases of $\mathrm{CO}_{2}$ concentration, leaves also close their stomata with increasing $D$ to prevent excessive transpiration when the atmospheric demand is high. Stomatal conductance typically scales as $\approx 1 / 2 \log (D) \approx$ $D^{-1 / 2}$ [Oren et al., 1999; Katul et al., 2009] so that transpiration may increase as $D$ increases up to a maximum, after which it stabilizes or even declines due to stomatal closure 
[Monteith, 1995]. These contributions are now discussed, commencing at a basic level- the leaf scale.

\section{LEAF-SCALE PROCESSES}

[22] Leaf-scale transpiration as governed by the plant biochemical demand for $\mathrm{CO}_{2}$ under high soil moisture conditions is first considered. When the biochemical demand for $\mathrm{CO}_{2}$ is combined with a Fickian mass transfer formulation, the problem remains mathematically open until stomatal conductance is prescribed. One "closure" scheme assumes that stomatal aperture is autonomously regulated so as to maximize the carbon gain while minimizing water loss, which leads to an analytical expression for leaf-scale conductance. How well this formulation predicts the effects of elevated atmospheric $\mathrm{CO}_{2}$ and increases of $D$ is first explored. Next, the regulation of leaf conductance by stomata during soil moisture stress is discussed using a wealth of gas exchange measurements in drought studies.

\subsection{Basic Equations}

[23] Mass transfer of $\mathrm{CO}_{2}$ and water vapor through leaves occurs via Fickian diffusion and can be expressed as

$$
f_{c}=g\left(c_{a}-c_{i}\right) ; \quad f_{e}=a g\left(e_{i}-e_{a}\right) \approx a g D,
$$

where $f_{c}$ is the $\mathrm{CO}_{2}$ flux, $f_{e}$ is, as before, the water vapor flux from leaves (expressed per unit leaf area), $g$ here is the "leafscale" stomatal conductance to $\mathrm{CO}_{2}, c_{a}$ is ambient and $c_{i}$ intercellular $\mathrm{CO}_{2}$ concentration, respectively, $a=1.6$ is the relative diffusivity of water vapor with respect to carbon dioxide, $e_{i}$ is the intercellular and $e_{a}$ the actual vapor pressure, and $D$ is the vapor pressure deficit representing $e_{i}-e_{a}$ when the leaf is well coupled to the atmosphere. When leaf dark respiration is small with respect to $f_{c}$, the biochemical demand for $\mathrm{CO}_{2}$ can be described by the photosynthesis model [Farquhar et al., 1980]

$$
f_{c}=\frac{a_{1}\left(c_{i}-c_{p}\right)}{a_{2}+c_{i}},
$$

where $c_{p}$ is the $\mathrm{CO}_{2}$ compensation point (or the $\mathrm{CO}_{2}$ concentration at which the net carbon dioxide assimilation rate is zero) and $a_{1}$ and $a_{2}$ are selected depending on whether the photosynthetic rate is light limited or Rubisco limited. Rubisco limitations occur when the temperature is sufficiently low so that the Rubisco enzyme limits the carbon fixation. When expressed in terms of $g$, equations (11) and (12) can be combined to yield [Katul et al., 2010]

$$
\frac{c_{i}}{c_{a}}=\frac{1}{2}+\frac{-a_{1}-a_{2} g+\sqrt{\left(a_{1}+\left(a_{2}-c_{a}\right) g\right)^{2}+4 g\left(a_{1} c_{p}+a_{2} c_{a} g\right)}}{2 g c_{a}} .
$$

and

$f_{c}=\frac{1}{2}\left(a_{1}+\left(a_{2}+c_{a}\right) g-\sqrt{\left(a_{1}+g\left(a_{2}-c_{a}\right)\right)^{2}+4 g\left(a_{1} c_{p}+a_{2} c_{a} g\right)}\right)$.
Equations (13) and (14) are nonlinear in $g$ and are not mathematically "closed," requiring one additional independent formulation of $g$ to compute $f_{c}$ and $c_{i}$. A number of physiological models have been proposed to close this system and are reviewed elsewhere [Damour et al., 2010]. These models generally fall into three categories. One category uses semiempirical formulations to link $g$ to environmental parameters [Jarvis, 1976] or to $f_{c}$ [Collatz et al., 1991; Leuning, 1995]. Such formulations are widely used in current climate models [Sellers et al., 1996]. A second category follows the so-called hydromechanical approach, which resolves pressure differences between the guard cells and the epidermis that ultimately drive stomatal movements [Dewar, 2002; Buckley et al., 2003]. Such models are physically based but require a priori plant physiological and hydromechanical parameters that are still seldom available and are outside the scope of this review. The third category assumes that stomata optimally regulate their aperture to maximize carbon gain per unit water lost without resolving all the details of the signaling mechanisms to the guard cells [Cowan and Farquhar, 1977; Cowan, 1986; Givnish and Vermeij, 1976; Hari et al., 1986]. Unlike the semiempirical models, optimization approaches do not a priori assume how $g$ responds to environmental drivers but attempt to derive such responses from an optimality hypothesis.

\subsection{An Optimality Hypothesis}

[24] As earlier mentioned, $f_{e}$ is a "cost" incurred by the plant when uptaking $\mathrm{CO}_{2}$. This premise was used to arrive at a closure hypothesis for equations (13) and (14). In this approach, an objective function to be maximized by the plants can be defined as

$$
\begin{aligned}
F_{n l}(g)=f_{c}-\lambda f_{e}= & \frac{1}{2}\left(a_{1}+\left(a_{1}+c_{a}\right) g\right. \\
& \left.-\sqrt{\left(a_{1}+g\left(a_{2}-c_{a}\right)\right)^{2}+4 g\left(a_{1} c_{p}+a_{2} c_{a} g\right)}\right) \\
& -\lambda(a g D) .
\end{aligned}
$$

By hypothesizing that stomatal aperture is regulated so that $g$ maximizes the carbon gain $\left(=f_{c}\right)$ for a given water loss $\left(=f_{e}>0\right.$ in units of carbon) and for a species-specific cost parameter $\lambda$, an expression for $g$ can be derived. While $\lambda$ is assumed to be approximately constant over a day, it may vary due to changes in soil moisture and atmospheric $\mathrm{CO}_{2}$ concentration (as discussed in sections 3.3 and 3.4), reflecting slowly changing dynamic constraints in the optimization problem. Such a maximization condition can be expressed as $\partial F_{n l}(g) / \partial g=0$ (i.e., $g$ is the variable controlled by the leaf), from which $g$ is obtained as

$$
\begin{aligned}
g= & \frac{-a_{1}\left(a_{2}-c_{a}+2 c_{p}\right)}{\left(a_{2}+c_{a}\right)^{2}} \\
& +\frac{\sqrt{a D \lambda a_{1}^{2}\left(c_{a}-c_{p}\right)\left(a_{2}+c_{p}\right)\left(a_{2}+c_{a}-2 a D \lambda\right)^{2}\left(a_{2}+c_{a}-a D \lambda\right)}}{a D \lambda\left(a_{2}+c_{a}\right)^{2}\left(a_{2}+c_{a}-a D \lambda\right)} .
\end{aligned}
$$


A simpler expression can be derived by linearizing the biochemical demand function of equation (12) with respect to $c_{i}$, now given as [Katul et al., 2009, 2010; Manzoni et al., 2011b]

$$
f_{c}=\frac{a_{1}\left(c_{i}-c_{p}\right)}{a_{2}+s c_{a}}
$$

where $s$ can be treated as a long-term $c_{i} / c_{a}$. This linearization, however, preserves the nonlinear increase of $f_{c}$ with increasing $c_{a}$. Combining the linearized biochemical demand function in equation (17) with equation (11), the objective function is now found as

$$
F_{l i}=f_{c}-\lambda f_{e}=\frac{g a_{1}\left(c_{a}-c_{p}\right)}{a_{1}+g\left(a_{2}+s c_{a}\right)}-\lambda(a g D) .
$$

As before, differentiating with respect to $g$, setting $\partial F_{l i}(g) /$ $\partial g=0$, and solving for $g$ results in [Hari et al., 1986; Katul et al., 2009, 2010]

$$
g=\left(\frac{a_{1}}{a_{2}+s c_{a}}\right)\left(-1+\left(\frac{c_{a}-c_{p}}{a \lambda D}\right)^{1 / 2}\right) .
$$

Hence, the closed form expressions for $c_{i}$ and $f_{c}$ can be derived from equations (13) and (14) as

$$
\begin{gathered}
\frac{c_{i}}{c_{a}}=1-\sqrt{\frac{a \lambda}{c_{a}-c_{p}}} D^{1 / 2}, \\
f_{c}=\frac{a_{1}\left(c_{a}-c_{p}\right)}{a_{2}+s c_{a}}\left(1-\sqrt{\frac{a \lambda}{c_{a}-c_{p}}} D^{1 / 2}\right) .
\end{gathered}
$$

Equation (20) provides the link between the marginal water use efficiency (WUE) and the ratio of internal to atmospheric $\mathrm{CO}_{2}$ concentrations, thus offering an opportunity to compute long-term $\lambda$ using stable isotope-based estimates of $c_{i} / c_{a}$. Equations (19) and (21) can also be rearranged to yield

$$
g=\sqrt{\frac{c_{a}-c_{p}}{a \lambda}} \frac{f_{c}}{\left(c_{a}-c_{p}\right)} D^{-1 / 2},
$$

which shows that a linear relationship between $g$ and $f_{c} /\left(c_{a}-\right.$ $c_{p}$ ) emerges from this linearized optimality model provided $\lambda$ varies linearly with $c_{a}$, which is considered next.

\subsection{Stomatal Optimization Under Increasing Atmospheric $\mathrm{CO}_{2}$}

[25] A number of studies have shown that $\lambda$ scales approximately linearly with $c_{a}$ [Katul et al., 2010; Manzoni et al., 2011b]. If this linearized scaling is expressed as $\lambda \approx$ $\lambda_{o} c_{a} / c_{o}$, then

$$
g=m \frac{f_{c}}{c_{a}-c_{p}} D^{-1 / 2}
$$

where $\lambda_{\mathrm{o}}$ is the intrinsic marginal water use efficiency defined at the growth atmospheric $\mathrm{CO}_{2}$ concentration $\left(\mathrm{c}_{\mathrm{o}}=\right.$
$380 \mathrm{ppm}$ ) and $m$ is a sensitivity parameter given as $\sqrt{c_{o}\left(1-c_{p} / c_{a}\right) /\left(a \lambda_{o}\right)}$. If $c_{p} / c_{a} \ll 1$, then $m \approx \sqrt{c_{o} /\left(a \lambda_{o}\right)}$ is a constant. Equation (23) becomes identical to the BallBerry (superscripted as BB) and Leuning (superscripted as LEU) semiempirical models [Collatz et al., 1991; Leuning, 1995; Medlyn et al., 2011], given by

$$
\begin{aligned}
& g_{\mathrm{LEU}} \approx m_{\mathrm{LEU}} \frac{f_{c}}{c_{a}-c_{p}}\left(1+\frac{D}{D_{o}}\right)^{-1}, \\
& g_{\mathrm{BB}} \approx m_{\mathrm{BB}} \frac{f_{c}}{c_{a}-c_{p}} \mathrm{RH},
\end{aligned}
$$

except that the vapor pressure deficit reduction function predicted from the optimization here is $D^{-1 / 2}$ instead of the $\left(1+D / D_{o}\right)^{-1}$ function assumed by Leuning, where $D_{o}$ is a normalizing constant, and the sensitivity parameter of the Leuning model $m_{\mathrm{LEU}}$ is linked to $m \approx \sqrt{c_{o} /\left(a \lambda_{o}\right)}$. Likewise, the linearized optimality result here is analogous to the BallBerry model if $D^{-1 / 2}$ is replaced by air relative humidity $(\mathrm{RH})$. It should be emphasized that the $D^{-1 / 2}$ dependence and the linearity between $g$ and $f_{c} /\left(c_{a}-c_{p}\right)$ are not a priori assumed (as in previous semiempirical models), but both are outcomes of the optimization hypothesis. With regards to the use of the Ball-Berry or the Leuning formulations, recall that climate models predict a constant RH with future climate and an increasing $D$, which can result in very different decreases of conductance when assessing the effects of future climate scenarios on the water cycle using equation (24). Finally, the linearized optimality results show that the instantaneous WUE can be related to the intrinsic marginal water use efficiency $\lambda_{o}$ as

$$
\mathrm{WUE}=\frac{f_{c}}{f_{e}} \approx c_{a} \sqrt{\frac{\lambda_{o}}{c_{o}}} \frac{1}{\sqrt{a D}} .
$$

For a constant $\lambda_{o}$, WUE linearly increases with increasing $c_{a}$ and nonlinearly decreases with increasing $D$. Hence, unlike the marginal water use efficiency $\lambda_{o}$, the flux-based water use efficiency is not an "intrinsic" plant property and varies with external environmental conditions. These predictions agree with gas exchange measurements collected in a grassland subject to a continuous $\mathrm{CO}_{2}$ gradient (Temple, Texas, see Anderson et al. [2001] and Fay et al. [2009]) and in a Pinus taeda plantation at the Duke Forest FACE facility, which employed an atmospheric enrichment of $200 \mathrm{ppm}$ above ambient (Figure 3). When leaf gas exchange data sets are combined for ambient and enriched conditions, predictions from the linear optimality model and leaf-scale field measurements can be compared assuming $\lambda=\left(\lambda_{o} / c_{o}\right) c_{a}$. The agreement in Figure 3 suggests that $\lambda_{o}$ is approximately constant, while $\lambda$ is likely to vary linearly with $c_{a}$, vary linearly with $c_{a}$ [Katul et al., 2010, Manzoni et al., 2011b], contradicting recent claims that $\lambda$ is independent of $c_{a}$ [Medlyn et al., 2011]. They also contradict recent claims that $\lambda$ is independent of $c_{a}$ [Medlyn et al., 2011]. Results from these optimality solutions and leaf gas exchange measurements collected from 
A

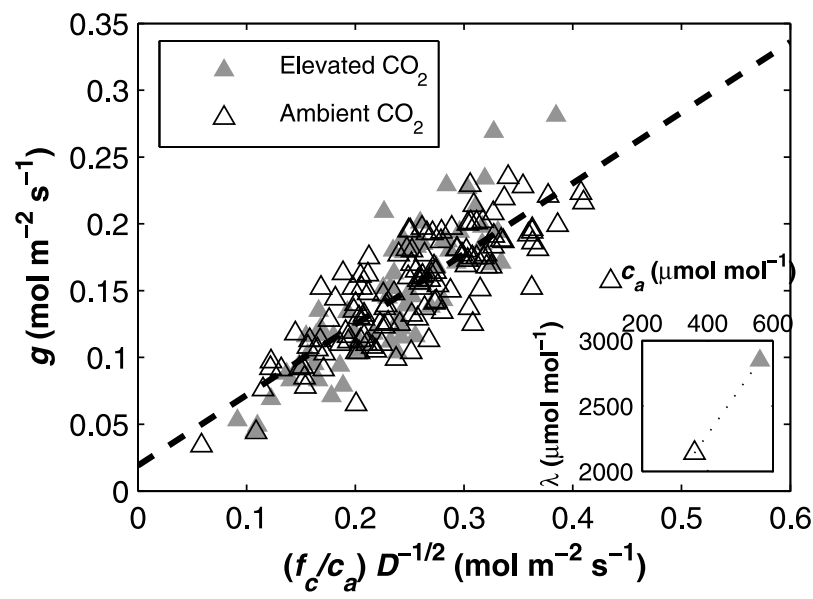

C

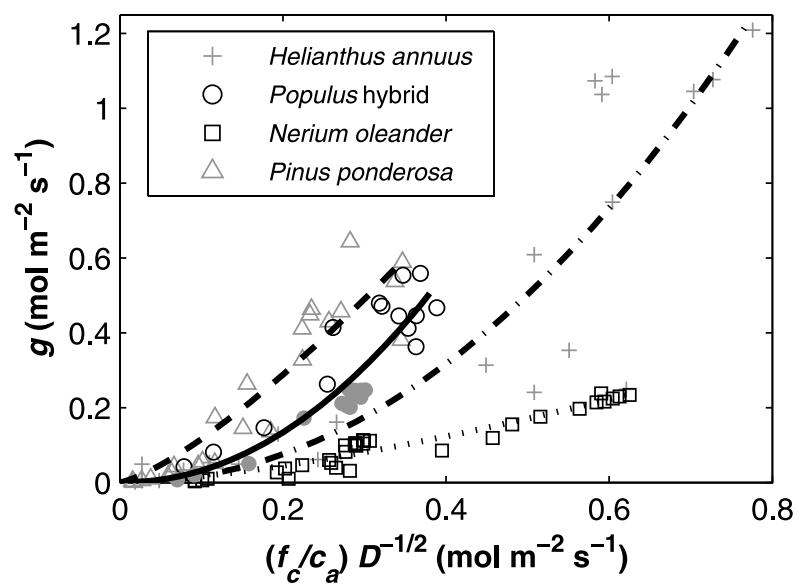

B

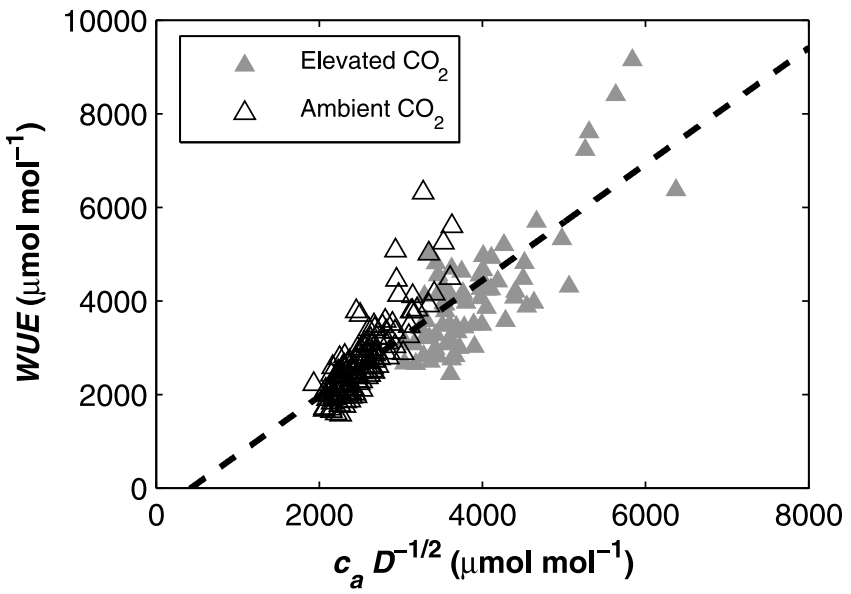

D

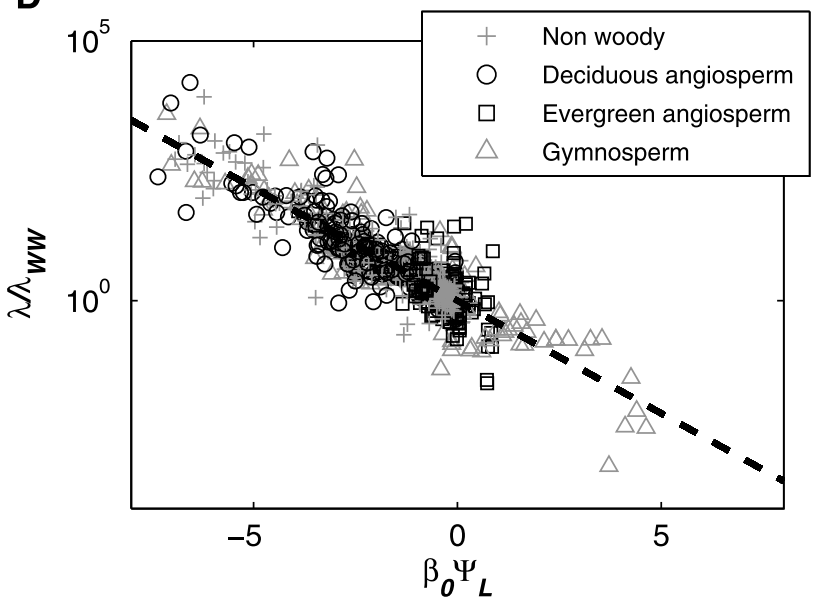

Figure 3. Testing the linearized optimality hypothesis under ambient (open symbols in the top panels) and elevated (filled symbols) atmospheric $\mathrm{CO}_{2}$ concentration $\left(c_{a}\right)$ conditions using gas exchange measurements. (a) Scaling of stomatal conductance $(g)$ and photosynthesis $\left(f_{c}\right)$ when vapor pressure deficit $(D)$ is changed, and (b) scaling of water use efficiency (WUE $=f_{c} / f_{e}$ ) and $c_{a}$ (data collected in a pine stand at the Duke Forest Free Air $\mathrm{CO}_{2}$ Enrichment facility, see Katul et al. [2010] for details). (c) Scaling of $g$ and $f_{c}$ when soil moisture declines (data for four species from major plant functional types are shown), and (d) effect of water status (here in terms of leaf water potential, $\psi_{L}$ ) on the marginal water use efficiency $(\lambda)$. Data in Figures 3c and 3d are from several sources; see Manzoni et al. [2011b] for details.

the FACE experiment agree that increasing $c_{a}$ by a factor of 1.6 above ambient and in the absence of any soil moisture limitations reduce $g$ (and hence $f_{e}$ ) by $\leq 15 \%$ while leaf photosynthesis increases by a factor of 1.4 .

\subsection{Stomatal Optimization Under Drought Stress}

[26] As soil moisture is reduced by ET during a dry-down period, $\lambda$ is expected to increase (i.e., $g$ must decrease) to optimize C uptake [Cowan, 1986; Mäkelä et al., 1996]. Experimental evidence from stable isotope studies [Prentice et al., 2011] shows that indeed the long-term $c_{i} / c_{a}$ declines as site aridity increases, corresponding to an increase in $\lambda$ as predicted in equation (20). Moreover, evidence from leaflevel gas exchange measurements along gradients of soil water availability (the marginal water use efficiency can be estimated as $\lambda\left(f_{c}, f_{e}\right)$ from equation (22)) confirms the theoretical predictions [Manzoni et al., 2011b]. When a residual conductance that is not controlled by the guard cells is retained, $\lambda$ is found to consistently increase as the leaf water potential, an indirect (but often observed) measure of soil water potential in the root zone, becomes more negative. Following Manzoni et al. [2011b], this relationship is well approximated by

$$
\lambda\left(\psi_{L}\right)=\lambda_{\mathrm{ww}} \frac{c_{a}}{c_{o}} \exp \left[-\beta_{o} \psi_{L}\right],
$$

where $\lambda_{\mathrm{ww}}$ is now the marginal water use efficiency in wellwatered conditions at the reference $\mathrm{CO}_{2}$ concentration, $\psi_{L}$ is the leaf potential, and $\beta_{0}$ is a slope parameter. The empirical relationship of equation (26) captures most of the variability 
in $\lambda$ across biomes and over a broad range of $\psi_{L}$. The values of $\lambda_{\mathrm{ww}}$ were found to be smaller in species grown in dry climates (not shown), indicating that stomatal conductance is relatively higher and water use less conservative then in mesic species when water is available. It is possible that this pattern represents a strategy adopted to outcompete other species (and physical processes causing water losses) by using water rapidly whenever it becomes available and by resisting drought conditions thereafter [DeLucia and Heckathorn, 1989]. The formulation proposed here ignores any modifications introduced by the mesophyll conductance (see Figure 1), though its importance relative to the stomatal conductance under drought conditions remains a subject of research [Lawlor and Cornic, 2002; Lawlor and Tezara, 2009]. A revised optimality hypothesis formulation that accommodates mesophyll conductance was recently proposed in the context of salinity stress [Volpe et al., 2011], though phytotoxic effects directly associated with salinity prevent direct extrapolations of these results to drought stress. At a more fundamental level, equation (26) neglects the biophysical and biochemical mechanisms of the water stress response [Tardieu and Davies, 1993; Buckley et al., 2003] by assuming that stomata evolved to behave optimally with regard to $\mathrm{CO}_{2}$ uptake. Linking the optimality hypothesis to evolutionary, biophysical, and biochemical mechanisms would be a natural development worth pursuing.

\section{UPSCALING LEAF PROCESSES}

[27] Quantifying water vapor exchanges between leaves and their local environment is made difficult by interactions in which the local environment exerts controls over water vapor exchange at the leaf surface (e.g., via $D$ ) and leaves have the capacity to partially regulate their own local environment through stomatal opening and closure. This interaction is complicated by the vertical distribution of foliage area within the canopy volume, resulting in significant vertical gradients in radiation load and airflow regimes. The nonlinearity in leaf physiological responses (e.g., leaf-level photosynthesis and transpiration) to radiation further exacerbates the difficulty in "upscaling" $f_{e}$ to the canopy level [Campbell and Norman, 1998].

[28] To eliminate leaf-to-leaf variation of $f_{e}$ at a height $z$ from the forest floor, spatial averaging in a plane parallel to the ground surface is conducted and results in a mean continuity equation for water vapor inside the canopy under idealized conditions given as [e.g., Baldocchi and Meyers, 1998]

$$
\frac{\partial \bar{C}}{\partial t}=-\frac{\partial \overline{w^{\prime} C^{\prime}}}{\partial z}-S_{c}=0
$$

where $C$ is the water vapor concentration, $\overline{w^{\prime} C^{\prime}}$ is the turbulent flux of water vapor, $S_{c}$ is the planar-averaged sources of water vapor, and the overbar represents time and planar average [Finnigan, 2000; Raupach and Shaw, 1982]. This budget equation assumes that the flow is stationary (or that the statistics of the flow are steady, so $\partial \bar{C} / \partial t=0$ ), planar homogeneous (or that the statistics of the flow are uniform in a plane parallel to the ground surface so $\partial \bar{C} / \partial x=\partial \bar{C} / \partial y=0$, where $x$ and $y$ are longitudinal and lateral directions), and lacks any subsidence (so that the mean vertical velocity of the air is negligible). This budget equation is not mathematically closed because $S_{c}, \overline{w^{\prime} C^{\prime}}$, and $\bar{C}$ are all unknowns. Hence, two additional equations are needed to close the problem of describing $S_{c}, \overline{w^{\prime} C^{\prime}}$, and $\bar{C}$. Adopting the simplest turbulence closure scheme for relating $\overline{w^{\prime} C^{\prime}}$ to $\bar{C}$, hereafter referred to as K-theory, provides one additional equation given as [e.g., Garratt, 1992]

$$
\overline{w^{\prime} C^{\prime}}=-K_{e} \frac{\partial \bar{C}}{\partial z},
$$

where $K_{e}$ is the eddy diffusivity for scalars. Furthermore, if the entire layer-wise leaf area density $\operatorname{LAD}(z)$ contributes to scalar exchange, then

$$
S_{c}(z)=\operatorname{LAD}(z) f_{e}(z)
$$

where $f_{e}$ is the leaf transpiration given by the optimization theories described earlier (equations (11b) and (19)). It becomes immediately clear that modeling $f_{e}$ requires photosynthetic parameters and $c_{a}(z)$, which in turn requires modeling the radiation regime inside the canopy to assess the local $D$, leaf temperature, and whether light or Rubisco limits $f_{c}$. The need to account for $c_{a}(z)$ can be accommodated via an analogous mean continuity equation for $\mathrm{CO}_{2}$ concentration with a closure formulation and upscaling from leaf-tocanopy via leaf area density [Launiainen et al., 2011]. Moreover, vertical variations of the air and foliage temperature inside the canopy can be sufficiently large during the day, necessitating the addition of a third scalar, air temperature. One advantage of adding the heat budget and air temperature is that the leaf energy balance can be used as an additional constraint on ET via indirect effects on local $D$ [Manzoni et al., 2011a]. It also permits models to account for local thermal stratification inside the canopy and its impacts on the flow field and $K_{e}$. It is the modeling of this flow field inside canopies that remains uncertain and poses significant challenges. Hence, it is logical to ask how detailed a turbulence closure model needs to be to resolve the dynamics of the canopy-scale ET, sensible heat flux, and $\mathrm{CO}_{2}$ fluxes above the vegetation. Using models described elsewhere [Juang et al., 2008], first-order (e.g., equation (28)), secondorder, and third-order closure schemes have been applied to scalar (water vapor, $\mathrm{CO}_{2}$, and temperature) and momentum transfer. The results are compared against a zeroth-order scheme that assumes that mean scalar concentration profiles are uniform and set to their value measured above the canopy (i.e., well mixed). Any bidirectional interactions between plants and their microenvironment are suppressed by this well-mixed assumption. Higher-order closure schemes are also employed here to alleviate some of the limitations of first-order closure principles [Finnigan, 2000] at the expense of introducing many more budget equations for triple and other mixed moments (in excess of 50 equations for the third- 
order closure scheme). The model data comparisons suggest that accounting for the interaction between the canopy and its microclimate, even at the first-order closure level, improves the modeled latent and sensible heat fluxes [Juang et al., 2008]. Suppressing the interaction between the canopy and its microclimate by assuming the air temperature, water vapor, and $\mathrm{CO}_{2}$ concentration are well mixed inside the canopy air space and set to their time-evolving values measured above the canopy impacts primarily the sensible heat flux, which then leads to large errors in the latent heat flux when enforcing the energy balance [Juang et al., 2008]. Higher-order closure schemes (beyond first order or Ktheory) also confer no clear benefits to model skill, at least when the variables of interest are scalar fluxes above the canopy [Juang et al., 2008].

[29] Up to this point, the interaction between the canopy and its environment made use of a known leaf area density when upscaling from leaf to canopy. However, any analysis of future climate scenario must resolve the effects of elevated atmospheric $\mathrm{CO}_{2}$ and increased vapor pressure deficit on leaf area density. The effect of elevated atmospheric $\mathrm{CO}_{2}$ on leaf area density (or leaf area index (LAI), expressing leaf area per unit of ground area), has been assessed both based on theory [Woodward, 1990] and experiments [McCarthy et al., 2007]. Where increased atmospheric $\mathrm{CO}_{2}$ results in higher photosynthesis and, thus, greater availability of carbohydrates, and plants are able to extract nutrients from the soil to support the construction of extra tissue, LAI may increase. Whether it will actually increase depends on the factors limiting LAI. For example, in one moist temperate plantation of Liquidambar styraciflua, large decreases of stomatal conductance under elevated atmospheric $\mathrm{CO}_{2}$ translated into much smaller savings of water because boundary layer conductance was low. The small savings of water on the background of little soil moisture limitation at that site produced only a marginal increase in LAI [Warren et al., 2011b]. Furthermore, drought actually caused a reduction in LAI under elevated $\mathrm{CO}_{2}$ due to carbohydrate deficiency associated with photosynthesis limited by low conductance [Warren et al., 2011a]. Indeed, in canopies not well coupled to the atmosphere (i.e., with low aerodynamic conductance), stomatal closure triggers several feedback processes maintaining a conservative transpiration rate despite the reduction of stomatal conductance [Jarvis and McNaughton, 1986], leading to small effects on LAI [Woodward, 1990]. In contrast, in well-coupled canopies of water limited forests, stomatal closure due to elevated atmospheric $\mathrm{CO}_{2}$ may result in water savings that can be used to increase LAI. The increase in LAI will reduce somewhat the amount of throughfall precipitation and allow canopy transpiration to reach levels similar to those under current atmospheric $\mathrm{CO}_{2}$, thus total ET will remain unaltered [Woodward, 1990]. This argument is analogous to an earlier hypothesis put forth by Roberts as to why forest transpiration is a "conservative" hydrologic flux [Roberts, 1983]. The pine canopy at the Duke FACE site is well coupled, and elevated $\mathrm{CO}_{2}$ indeed caused a $14 \%$ increase in LAI [McCarthy et al., 2007], but contrary to the theory, reductions in stomatal conductance occurred due to an indirect effect of decreasing average light level in the canopy with increasing LAI, and later due to changes in plant hydraulic properties [Domec et al., 2009, 2010], but not due to direct effect of $\mathrm{CO}_{2}$. It is likely that the direct effects of elevated $\mathrm{CO}_{2}$ on LAI in that study were simply a reflection of increased photosynthesis and carbohydrate availability as $\mathrm{CO}_{2}$ concentration increased but canopy conductance was unaffected [Schäfer et al., 2003]. Thus, experimental evidence of $\mathrm{CO}_{2}$-induced increases of LAI in well-coupled canopies supporting the theoretical predictions are still lacking, in part reflecting the scarcity of such studies, and in part because studies done on conifer species are not likely to support the theory because conifers have little direct stomatal response to elevated $\mathrm{CO}_{2}$ [Pataki et al., 1998; Medlyn et al., 2001].

[30] Low precipitation causes not only a reduction in soil moisture but also an increase in D [Oishi et al., 2010]. Thus, maximum stomatal conductance decreases with drought (as discussed earlier through increased $\lambda$ ), and the accompanying higher vapor pressure deficit keeps stomata conductance $\left(g \sim D^{-1 / 2}\right.$, see equation (22)) below the maximum most of the day. In combination, this reduces the carbohydrates available to plants. Where elevated $\mathrm{CO}_{2}$ produced an even greater stomatal closure, the carbon balance of individual leaves became negative, resulting in loss of leaves and a reduction of LAI [Warren et al., 2011a]. Thus, depending on the species, canopy and site conditions, and the degree to which vapor pressure deficit will increase with atmospheric concentrations of $\mathrm{CO}_{2}$ (as earlier described through $\delta T_{a}$ ), the combined effects on LAI may range from positive to negative, mediated through direct stomatal responses that influence both soil moisture and photosynthesis and indirect effects of plant hydraulics. For modeling ET responses to changes of atmospheric $\mathrm{CO}_{2}$ and vapor pressure deficit, not only the conditions during drought must be considered, but the carryover effects of drought on LAI must be accounted for during following years [Warren et al., 2011a]. A multiscale modeling strategy to account for these effects and concomitant feedbacks using the upscaling scheme earlier described has been proposed and tested for the pine forest [Siqueira et al., 2006], though testing on other types of forests is required.

\section{SOIL-PLANT PROCESSES}

[31] Having discussed the mechanisms controlling the upscaling of $f_{e}$ to the canopy level when water supply was not limiting (as in sections 3.1-3.3), this section explores issues pertinent to the role soil moisture plays in limiting canopy-scale transpiration [Hsiao, 1973]. In equation (23), it was shown that the cost of water to the plant (in units of carbon) rapidly increases with declining leaf pressure $\left(\psi_{L}\right)$, which itself varies with the soil moisture state and the canopy upscaled $f_{e}$. To link $\psi_{L}$ to the soil water status, the continuity equation for the water flux from the soil to the leaves $\left(=T_{r}\right)$ can be written following the electrical analogy 
as [van den Honert, 1948; Novick et al., 2009; Manzoni et al., 2012]

$$
\begin{aligned}
T_{r} & =\int_{0}^{h_{c}} S_{c}(z) d z=\int_{0}^{h_{c}} \operatorname{LAD}(z) f_{e}(z) d z \\
& =g_{S R}\left(\psi_{S}-\psi_{R}\right) \approx g_{R L}\left(\psi_{R}-\psi_{L}-\rho_{w} g_{a} h_{c}\right),
\end{aligned}
$$

where $g_{S R}$ and $g_{R L}$ are now the soil-to-root and root-to-leaf xylem conductance, respectively, $\psi_{R}$ and $\psi_{S}$ are the water pressure in the root and soil, respectively, $\rho_{w}$ is the water density, $g_{a}$ is the gravitational acceleration, and $h_{c}$ is the tree height (used here as a surrogate for the path length from the soil to the leaf as a first-order approximation). Recall that $f_{e}$ decreases with reduced $\psi_{L}$, as can be inferred by equations (22) and (26). The $g_{S R}$ depends on an interfacial hydraulic conductivity at the soil-root interface $\left(=K_{r}\right)$ and a soil hydraulic conductivity that varies with local soil moisture content or $\psi_{S}$ via a soil water retention curve [Sperry et al., 1998; Williams et al., 1996; Siqueira et al., 2008, 2009]. The dependence of $g_{R L}$ on xylem pressure is more complex but existing approaches rely on the so-called cohesion-tension (CT) theory [Bonner, 1959; Dixon, 1914; van den Honert, 1948] expanded upon elsewhere [Angeles et al., 2004; Tyree and Sperry, 1989; Wheeler and Stroock, 2008]. According to CT, liquid water in the xylem conduits is under negative (or subatmospheric) pressures that range between soil $(\sim-10 \mathrm{kPa})$ and atmospheric water potentials $\left(\sim-100 \mathrm{MPa}\right.$ at $45 \% \mathrm{RH}$ and $\left.15^{\circ} \mathrm{C}\right)$. Xylem water pressures are on the order of $-1 \mathrm{MPa}$, although in some species under dry conditions, pressures as low as $-8 \mathrm{MPa}$ can occur [Sperry, 2000]. These liquid pressures are well below the vapor pressure of water resulting in a thermodynamic state that is prone to vaporization, or cavitation, which must be prevented if the continuity of the water column is to be maintained. When vapor is formed in the conduit conduction is impeded [Tyree and Sperry, 1989]. Reduced conduction, in turn, reduces transpiration and the water potential in the downstream parts of the plant, causing water stress at the leaf level and reduced $\mathrm{CO}_{2}$ uptake [Vico and Porporato, 2008; Lawlor and Tezara, 2009]. Refilling of embolized conduits can occur (even on a daily basis in some species), but it is costly, as it requires secretion of osmolites to induce vapor condensation and transport of water from nearby conduits and cells [Vesala et al., 2003; Zwieniecki and Holbrook, 2009]. Thus, it appears that the plant water delivery system linking the supply (soil water) to the demand (inevitable loss of water vapor through stomates to allow carbon dioxide diffusion into leaves) is inherently vulnerable to cavitation. The functional relationship describing the variation of $g_{R L}$ as the xylem water potential declines, known as vulnerability curve, encodes all these mechanisms.

[32] The shape of the vulnerability curves depends on the xylem structure - specifically, the presence of rare but large pores that are more prone to cavitation and the density-related resistance of cell walls to implosion [Hacke et al., 2001; Wheeler et al., 2005]. These wood properties vary among plant functional groups, in particular between angiosperms and gymnosperms, resulting in large variation in the corresponding vulnerability curves. Angiosperms tend to be more hydraulically efficient (higher saturated conductivity), but also more sensitive to cavitation (less negative water potentials for a given cavitation threshold) than gymnosperms, because of their efficient xylem vessels [Maherali et al., 2004; Manzoni et al., 2012]. The tradeoff between efficiency and safety also emerges across species in angiosperms [Hacke et al., 2006], among populations grown in different environments [e.g., Corcuera et al., 2011], among individuals over time, as a drought progresses [e.g., Kolb and Sperry, 1999], and among soils of different texture and fertility [Hacke et al., 2000; Ewers et al., 2000]. These tradeoffs define a spectrum of hydraulic strategies that covary with the leaf-level traits, indicating a strong degree of coordination between liquidphase and gas-phase water transport that allows an efficient supply of water to the leaves and ultimately determines the outcome of species competition and success under a given climate [Manzoni et al., 2012].

[33] In larger-scale hydrologic and carbon cycling models, the reduction in transpiration with soil moisture is often specified a priori via a so-called "loss function" empirically describing how transpiration is reduced with decreasing soil moisture within the rooting zone [e.g., Laio et al., 2001]. A logical next step is to formulate mechanistic links between stomatal conductance, the vulnerability curves used in CT theory, soil hydraulic properties, rooting distribution, the interfacial hydraulic properties at the soil-root interface $\left(=K_{r}\right)$, and the loss function [Daly et al., 2004; Siqueira et al., 2008; Vico and Porporato, 2008]. Different ecophysiological drivers of this reduction in transpiration as soil moisture declines represent alternative strategies developed to cope with water stress at different time scales. Stomata respond rapidly to changes in $D$ and leaf water potential, but their sensitivity increases when root-derived phytohormones that integrate soil moisture changes through time accumulate in the leaf [Tardieu and Davies, 1993]. At the daily time scale, water storage in stems allows high transpiration rates to be sustained during peak atmospheric demand [Bohrer et al., 2005; Chuang et al., 2006; Scholz et al., 2007], whereas over the course of a drought the so-called water redistribution (HR) by roots becomes important, as discussed next.

[34] The vulnerability curves for the Duke Forest Loblolly pine stand and their relations to the soil moisture loss function over a prolonged drought are explored using model calculations [Siqueira et al., 2008, 2009]. In these model calculations, two flow patterns simultaneously occur in the soil system - the first pattern occurs at scales comparable to the root zone depth $(\sim \mathrm{m})$ and the second pattern occurs at length scales inversely related to root density $(\sim \mathrm{mm})$, taken here to represent the radial distance between rootlets [Mendel et al., 2002; Tuzet et al., 2003]. The model calculations were performed for three types of root density profiles: constant, linear, and power law in a silt clay soil; and three soil types: sand, silty clay, and clay for a linearly distributed root density profile. To emphasize the role of $K_{r}$, 

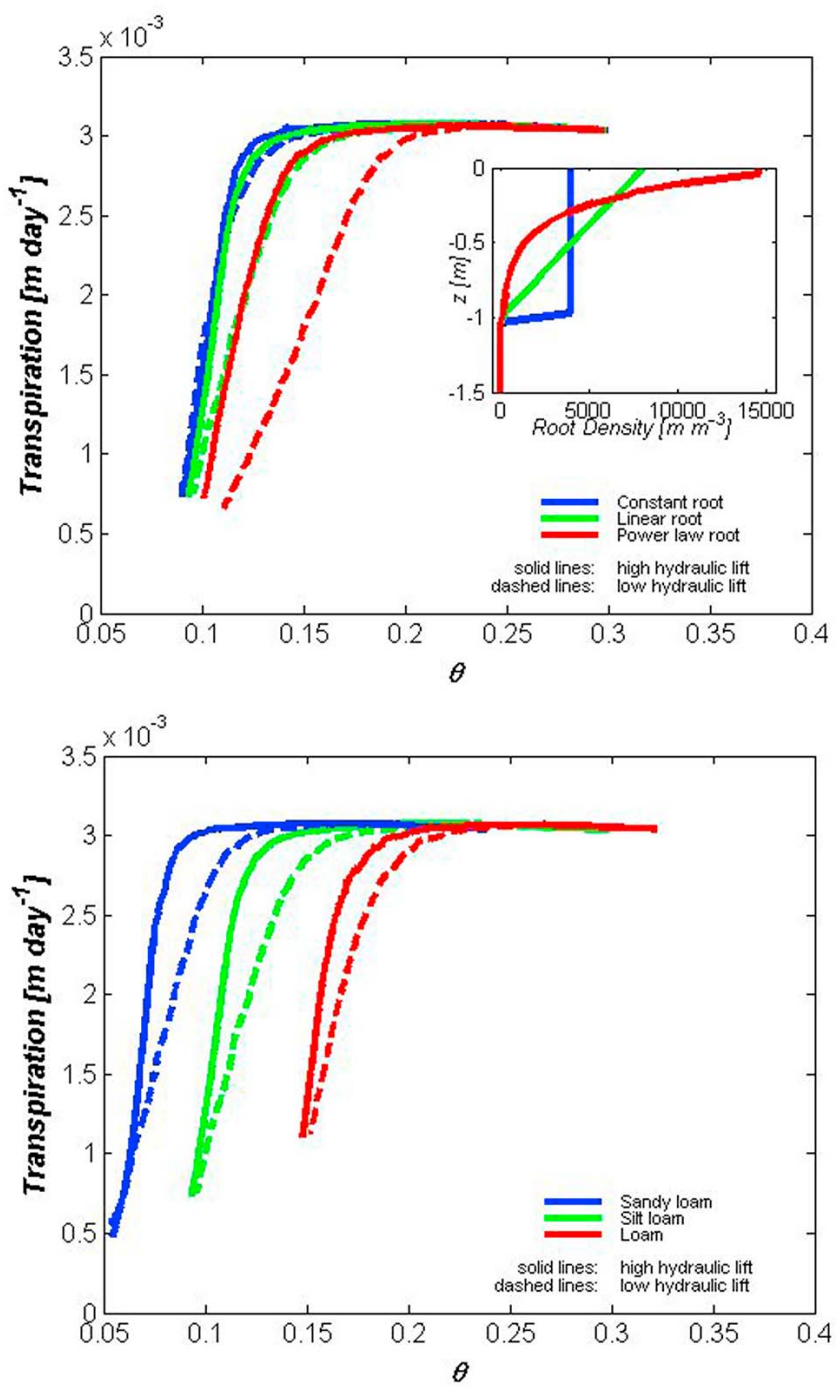

Figure 4. The "loss function" describing transpiration as a function of depth integrated soil water for high and low soilroot hydraulic conductivity $\left(K_{r}\right)$ and for (top) various root density profiles and (bottom) soil types. In these simulations, taken from model runs in Siqueira et al. [2008], the HR is dominated by a hydraulic lift (HL) occurring when $K_{r}$ is large. The solid lines are for high $\mathrm{HL}$ and the dashed lines are for low HL.

high and low values were chosen. The model calculations suggest that this choice regulates the strength of the HR. With sap flow and stable isotope measuring techniques proliferating over the last two decades [Domec et al., 2010; Emerman and Dawson, 1996], the occurrence of HR was reported for shrub, grasses and tree species and for temperate, tropical, and desert ecosystems [Caldwell et al., 1998; Horton and Hart, 1998; Oliveira et al., 2005]. In all cases modeled with rooting zone depth set to $1 \mathrm{~m}$, HR delays the onset of soil moisture stress within the rooting zone by some 20-40 days [Siqueira et al., 2008, 2009]. More importantly, Figure 4 shows that the loss function is a by-product of numerous processes governing the soil-plant-atmosphere system, including the passive strategies controlling HR. The effects of elevated HR on this loss function is to shift the onset of transpiration reductions to lower soil moisture of the upper root zone, thereby allowing the ecosystem to sequester more carbon, as found in recent field experiments [Domec et al., 2010]. Figure 4 further demonstrates that for a uniform rooting density profile, HR confers minor benefits to the plant. Additionally, a number of model calculations similar to the ones shown in Figure 4 were conducted with all combination of soil types and root distributions. It was concluded that the effectiveness of the HR is mainly controlled by the root vertical distribution, while the soil moisture levels at which HR is most effective appears to be dictated by the soil type.

[35] Over ontogenetic time scales, other strategies may be employed to cope with prolonged and frequent drought (especially in semiarid ecosystems), including drought deciduousness and investment in deep rooting systems [Borchert, 1994; Eamus and Prior, 2001; Guswa, 2010], as well as flexible growth patterns that favor water conservation [Maseda and Fernandez, 2006]. Of course, climatic changes leading to long-term decreases in water availability will also cause changes in species composition, resulting in ecosystems that are better adapted to drought conditions [e.g., McDowell et al., 2008].

\section{REGIONAL SCALE ET AND THE ROLE OF LANDSCAPE-SCALE HETEROGENEITY}

[36] Having linked leaf-level transpiration and carbon uptake, their upscaling to the canopy level, and the mitigating role of soil moisture redistribution at longer time scales (e.g., HR), the role of $f_{e}$ on modifying $\delta P / P$ at regional scales can now be considered [Pielke, 2001; Santanello et al., 2005] with a focus on natural and human induced landscape fragmentation. Fragmented landscapes are becoming one of the most widespread features of the modern world [Laurance, 2004], with important consequences for ET and initiation of convective rainfall [Giorgi and Avissar, 1997; Wang et al., 2000, Werth and Avissar, 2002, Negri et al., 2004, Wang et al., 2009]. Landscape fragmentation and heterogeneity prevents direct extrapolation of simplified slab or closure models such as the ones used in equation (28). This problem remains a scientific challenge because of the large number of interacting processes within the soil-plantatmosphere system that vary over a wide range of space and time scales. At the most basic level, below-ground and surface processes involve the dynamics of water movement from the soil into the atmosphere, the canopy aerodynamics regulating the transport of heat and water vapor from the canopy into the atmosphere, and the partitioning of net radiation into latent, sensible, and soil heat fluxes, which all impact the dynamics of mean air temperature and water vapor concentration in the ABL. On the other hand, the $\mathrm{ABL}$, with its mechanically and thermally produced turbulence, is a natural integrator of these surface processes with the larger and slower evolving synoptic scale processes impacting entrainment at its top [Konings et al., 2010]. The dynamics of these land surface fluxes and soil-plant-atmosphere state variables control the simultaneous growth of both the 
convective boundary layer (often modeled as a well-mixed slab) and the lifting condensation level (LCL), and thus their crossing. This crossing is a necessary but not sufficient condition for the formation of convective rainfall [Juang et al., 2007a, 2007b; Rogers and Fritsch, 1996]. What makes accounting for the effect of landscape fragmentation difficult is the interaction between the spatial structure of the fragmented landscape and the turbulent airflow within the $\mathrm{ABL}$, as well as the $\mathrm{ABL}$ height. The juxtaposition of the forest canopy with clear-cut regions affects not only the flow but also the localized energy partitioning via ET that can ultimately lead to localized rainfall events. It is now recognized that differential surface heating due to heterogeneity within the underlying surface can result in sustained atmospheric circulation over a wide range of spatial and temporal scales. Well-studied examples include sea breeze (and lake breeze) that are produced by thermal gradients between adjacent land and water bodies. During daytime conditions, the land surface warms up compared to the adjacent water body, and assuming air is an ideal gas, the interplay between pressure, air density, and temperature above a surface results in

$$
\frac{\delta P_{a}}{P_{a}}=\frac{\delta \rho}{\rho}+\frac{\delta T_{a}}{T_{a}}=\left(\frac{\delta n_{a}}{n_{a}}-\frac{\delta V_{a}}{V_{a}}\right)+\frac{\delta T_{a}}{T_{a}}
$$

where $n_{a}$ are the number of air and vapor molecules, $V_{a}$ is the volume of air above a unit surface area (which scales linearly with the ABL height), and $\rho$ is the air density. On the one hand, surface heating increases $\delta T_{a} / T_{a}$ over land, although this increase is much smaller than the growth in boundary layer height (and hence $V_{a}$ ). For example, a maximum daytime $\delta T_{a} \sim$ $10^{\circ} \mathrm{C}$ warming at a mean $T_{a}=27^{\circ} \mathrm{C}$ results in $\delta T_{a} / T_{a}<5 \%$. On the other hand, boundary layer growth over land (and hence $\delta V_{a} / V_{a}$ ) may reach fivefold, with early morning ABL heights as low as $200 \mathrm{~m}$ and daytime ABL heights in excess of $1000 \mathrm{~m}$. It is this growth that results in $\left|\delta V_{a} / V_{a}\right| \gg\left|\delta T_{a} / T_{a}\right|$ and regulates density and pressure gradients between the two surface types. That is, warmer air over land creates a zone of reduced density $(\delta \rho / \rho<0)$ due to an expansion of the boundary layer height and results in a reduced pressure above the land when compared to the adjacent water body. This pressure difference induces air movement (sensed as a breeze) from the water body region to the lower-pressure land surface region. The precise mechanism linking the generation of this pressure gradient to air movement will be described later via the conservation of momentum equations, known as the Navier-Stokes equations. At night, the reverse case occurs, with air flowing from the land to the adjacent water body. In short, buoyancy forces (i.e., $\delta \rho / \rho$ ) play a dominant role in generating and sustaining the dynamics of such pressure gradient-induced air movement, not the direct effect of air temperature fluctuations on pressure.

[37] With regards to large-scale natural and humaninduced land surface heterogeneity, often embedded within the land surface in the form of patches, the radiative and thermal properties of these patches can differ from those of their surroundings and can also produce horizontal pressure gradients sufficiently strong to generate a sort of "canopy breeze" (see Figure 5). This canopy breeze, if occurring on spatial scales much larger than the boundary layer height, can even sustain organized mesoscale circulation that can impact rainfall. Satellite images have already provided some evidence for the existence of organized circulation - strong enough to produce cumulus clouds [Roy and Avissar, 2002].

[38] Numerical simulation studies on the early phases of deforestation in Amazonia have explained how precipitation may be initially enhanced by such canopy breeze. This mechanism operates as follows: greater surface warming of a large area of bare soil relative to an adjacent large forest area of higher ET amplifies the pressure differences between the forested and the bare site-usually by late morning, when $\left|\delta V_{a} / V_{a}\right|$ is near its maximum. Eddies over the bare soil patches, energized by buoyant forces and assisted by air convergence from the surrounding forested regions (see Figure 5), can then form a narrow updraft zone thereby setting up the mesoscale circulations. This circulation then delivers the moist air originating from the upscaled forest ET and advected by the canopy breeze to the top of the atmospheric boundary layer, the height of which is likely to exceed the (reduced) lifting condensation level of the moist forest air. Hence, such canopy breeze, entirely produced by landscape heterogeneity, can enhance the local convective rainfall at scales of $10 \mathrm{~km}$. However, as shown in Figure 5, with further increases of deforested area, the amount of moisture in the atmosphere is reduced due to the reduced landscape LAI (at regional scale, $\mathrm{ET} \sim \operatorname{LAI} f_{e}$ ) such that the LCL becomes sufficiently high thereby reducing the probability that the ABL height crosses the LCL. For such a level of deforestation and reduced LAI, rainfall $\delta P / P$ decreases because of reduced ET.

[39] The prediction of the formation of canopy breeze by land surface heterogeneities and its subsequent effects on rainfall in Amazonia are among some of the successes of large-scale computational methods known as large eddy simulations (LES). It is clear from this case study that for any region with high variability in land use or topography, boundary layer dynamics, ET modeling, and its concomitant effect on water vapor concentration in the ABL must be faithfully reproduced. LES is a numerical technique that is particularly well suited to this aim. While it is not yet possible to simulate the entire range of turbulent motions in the atmosphere, it is possible to simulate a significant portion of the energy-containing scales of motion while accounting for the effects of the smallest-scale turbulent motions that are often locally homogeneous and isotropic. The largest scales of turbulence contain most of the kinetic energy, are influenced by the (heterogeneous) boundary conditions, and are responsible for most of the turbulent transport of water vapor, while the smallest turbulent scales behave in a more idealized manner and are more amenable to parameterization. This separation of scales is achieved mathematically by applying a low-pass spatial filter to the Navier-Stokes equations and, because the large-scale eddies are explicitly resolved, the technique for numerically solving these filtered Navier-Stokes equation is termed "large eddy simulations." For airflow that includes a canopy exchanging heat, water 


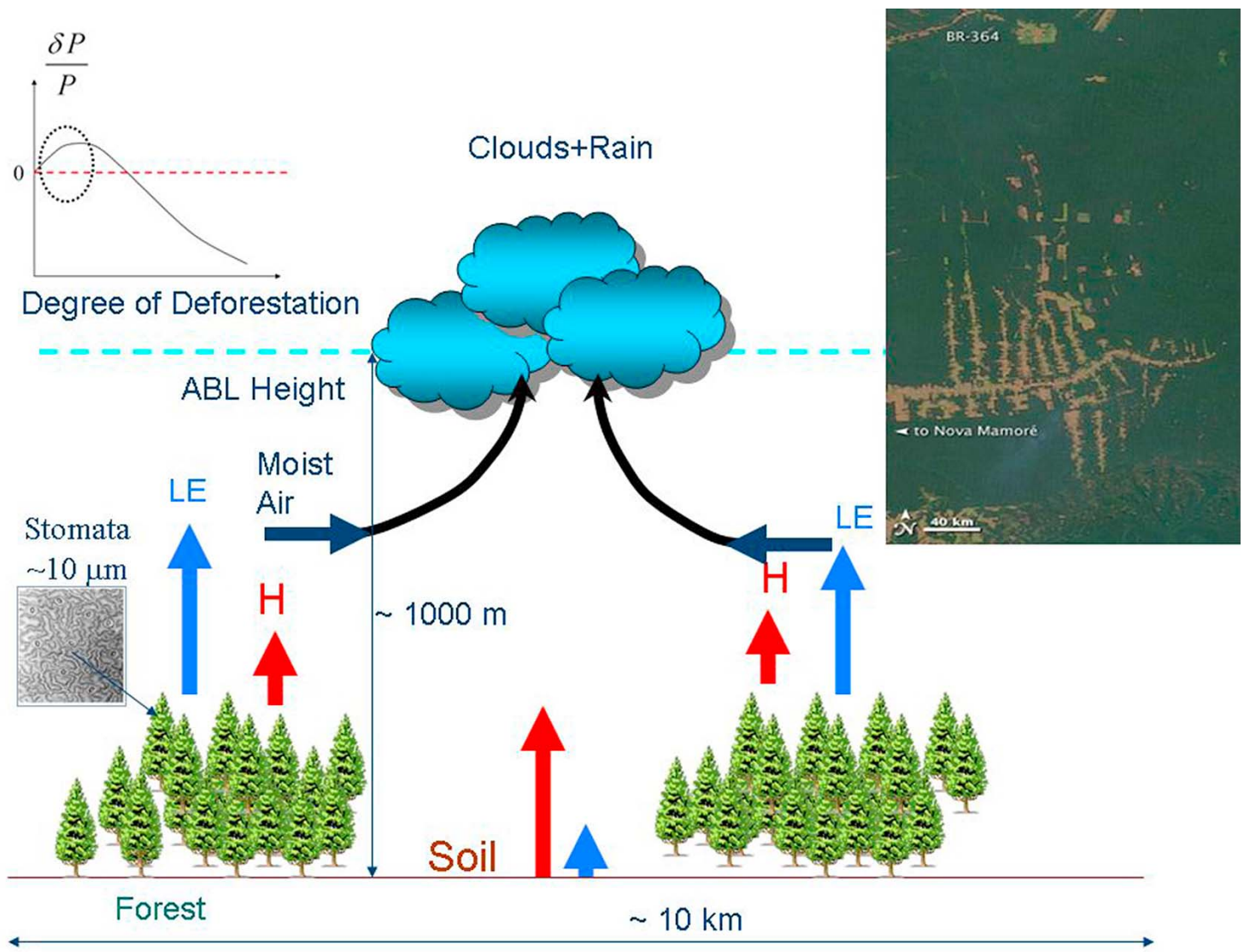

Figure 5. The effect of deforestation on water cycling and precipitation. The air temperature and pressure contrast between the forest (high-pressure zone) and the bare soil (low-pressure zone) induces a "canopy breeze" flow (resembling sea breeze during daytime). If the sensible heat flux is sufficiently large over an area of similar linear dimensions to the boundary layer height, then the energetic convective updrafts originating from the soil surface vertically lift to the top of the ABL the moist air originating and advecting from the forested area into the deforested area. This canopy breeze (flow of air from forest to bare soil area) and its vertical lifting by convective eddies can enhance the predisposition of rainfall because moist air has a lower lifting condensation level (LCL). However, if deforestation progresses further, the amount of water vapor in the atmosphere is reduced due to reduced regional ET $\left(=\mathrm{LAI} \times f_{e}\right)$; while this reduction results in a higher ABL height, the even higher LCL of the drier air reduces the predisposition to rainfall.

vapor, and $\mathrm{CO}_{2}$ with the atmosphere, the basic LES equations are given as a set of conservation laws describing conservation of fluid mass, momentum, heat, water vapor, and $\mathrm{CO}_{2}$ [Albertson et al., 2001]:

$$
\begin{aligned}
& \frac{\partial \tilde{u}_{m}}{\partial x_{m}}=0, \\
& \frac{\partial \tilde{u}_{i}}{\partial t}+\tilde{u}_{j} \frac{\partial \tilde{u}_{i}}{\partial x_{j}}=-\frac{\partial \tilde{p}}{\partial x_{i}}+\delta_{i 3} \frac{g_{a} \alpha_{T}}{\rho} \tilde{\theta}-\frac{\partial \tau_{i j}}{\partial x_{j}}-f_{i} \\
& \frac{\partial \tilde{\theta}}{\partial t}+\tilde{u}_{j} \frac{\partial \tilde{\theta}}{\partial x_{j}}=-\frac{\partial \pi_{j}^{\tilde{\theta}}}{\partial x_{j}}+s_{\tilde{\theta}} \\
& \frac{\partial \tilde{q}}{\partial t}+\tilde{u}_{j} \frac{\partial \tilde{q}}{\partial x_{j}}=-\frac{\partial \pi_{j}^{\tilde{q}}}{\partial x_{j}}+s_{\tilde{q}} \\
& \frac{\partial \tilde{c}}{\partial t}+\tilde{u}_{j} \frac{\partial \tilde{c}}{\partial x_{j}}=-\frac{\partial \pi_{j}^{\tilde{c}}}{\partial x_{j}}+s_{\tilde{c}}
\end{aligned}
$$

where $x_{i}\left(=x_{1}, x_{2}\right.$, and $x_{3}$; or $\left.x, y, z\right)$ represent spatial coordinates, $\tilde{u}_{i}$ is the velocity field (the tilde symbol is used to denote filtered fields), $\tilde{p}$ is the turbulent pressure, $\tilde{\theta}$ is the temperature field, $\tilde{q}$ is the water vapor mixing ratio, $\tilde{c}$ is the concentration of $\mathrm{CO}_{2}, f_{i}$ is the localized drag due to the presence of the canopy elements and varies with the local plant area density (often larger than the leaf area density due to the presence of other plant organs that obstruct the flow such as woody canopy elements) and a dimensionless canopy drag coefficient, $\rho$ is the density of air as before, $s_{\tilde{\theta}}, s_{\tilde{q}}$, $s_{\tilde{c}}$ are the localized source or sink terms of heat, water vapor and $\mathrm{CO}_{2}$, respectively inferred from the local leaf area density and the leaf-level fluxes (e.g., equation (29)), $\delta_{i 3}$ is the Kronecker delta, $g_{a}$ is the acceleration due to gravity, $\alpha_{T}$ is the thermal diffusivity, $\pi_{j}^{\tilde{\theta}}, \pi_{j}^{\tilde{q}}, \pi_{j}^{\tilde{c}}$ are subgrid-scale fluxes of heat, water vapor, and carbon dioxide, respectively, and $\tau_{i j}=$ $u_{i} u_{j}-\tilde{u}_{i} \tilde{u}_{j}$ is the unknown subgrid scale (SGS) stress term that must be modeled to close equation (32). Subscripts $i$ and $j$ follow the customary index notation throughout (i.e., a single index such as $i=1,2,3$ indicates a vector component and repeated indices represent summation). The approach 

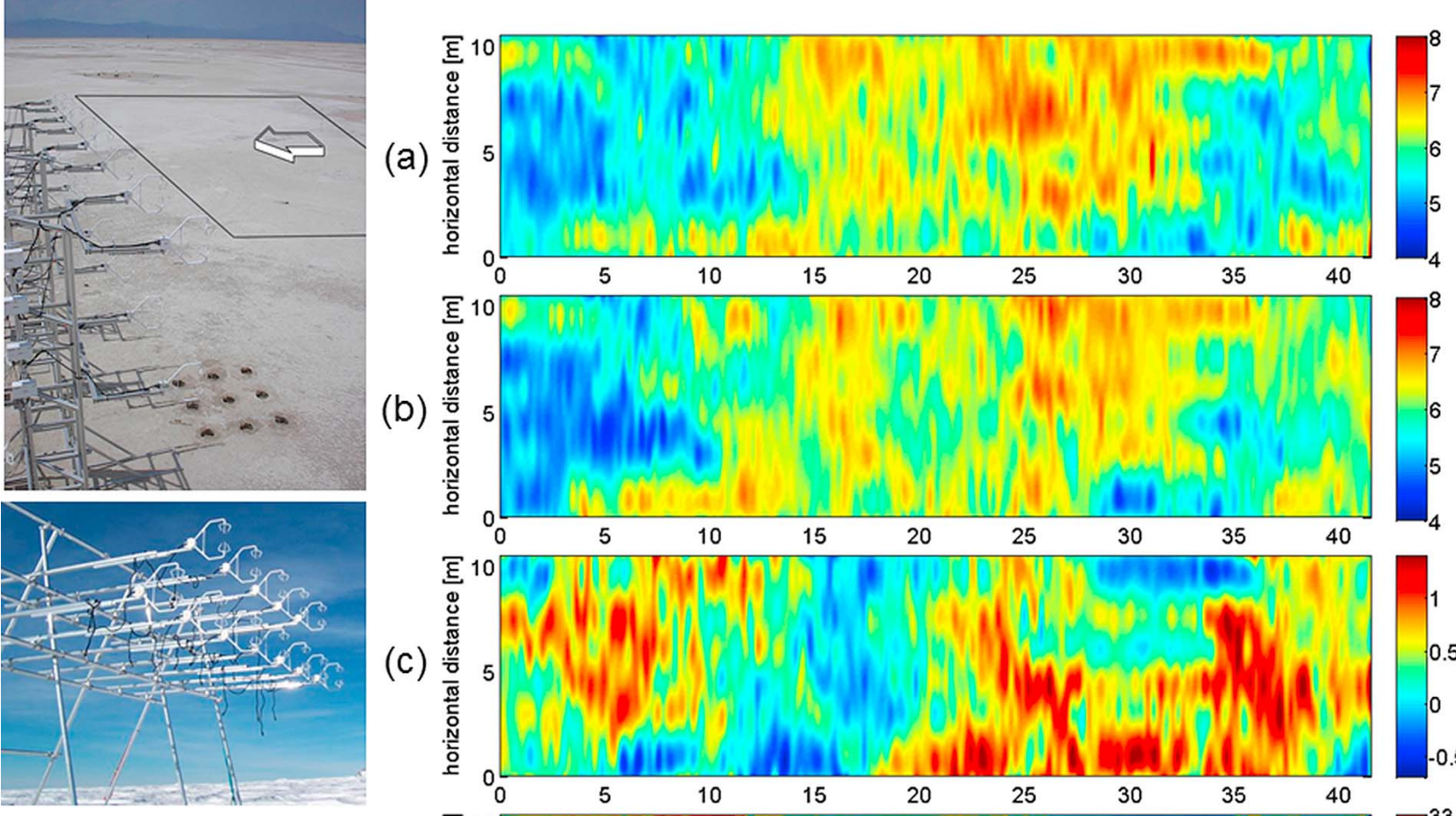

(b)

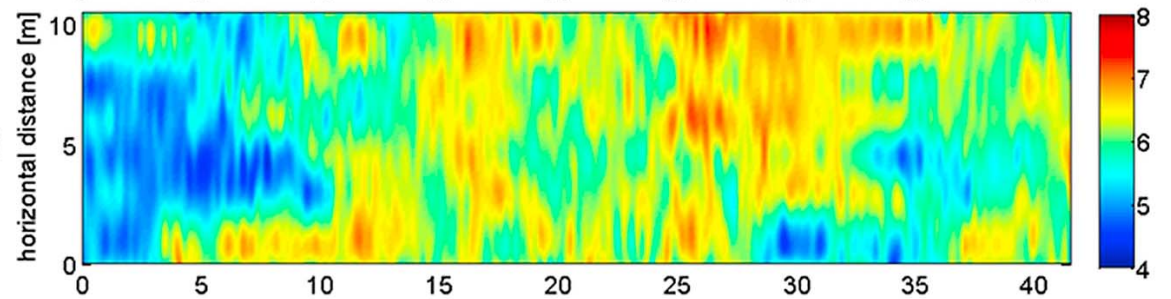

(c)
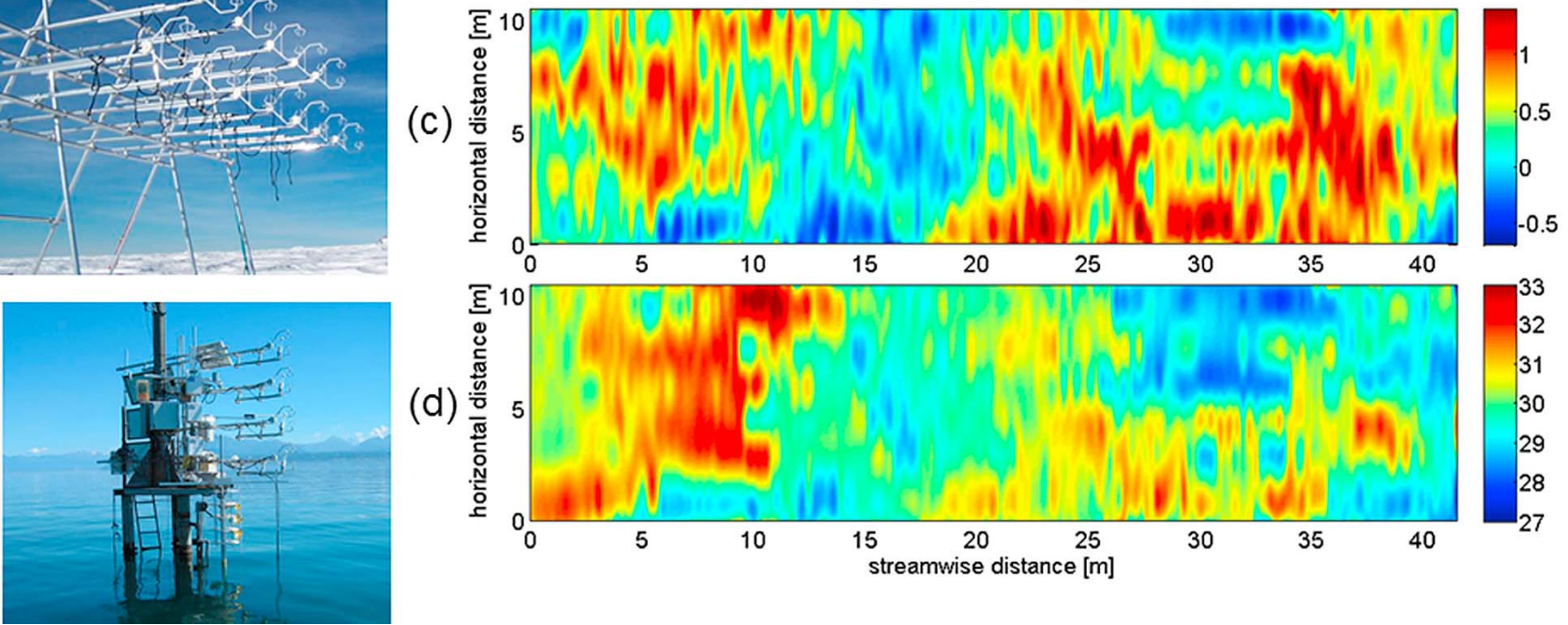

Figure 6. (left) Photographs of the sonic anemometer array experiment as well as the sheet resolved by the array in (top left) the west desert of Utah, SGS2002, (middle left) over the Plaine-Morte Glacier, Switzerland, and (bottom left) over a lake (Lake Geneva Switzerland). (right) A sample time series from the SGS 2002 experiment converted to stream-wise distance through application of Taylor's hypothesis, illustrating how turbulent structures are well resolved. The horizontal component of the velocity at the (a) lower and (b) upper levels shows an overall increased velocity with height, and more importantly, they show the coherency in space of the velocity patterns. It is also apparent that (c) the upward vertical velocity structures tend to carry (d) the warmer air parcels for the desert configuration.

can incorporate bidirectional interactions between the canopy and the atmosphere when representing $s_{\tilde{q}}=\operatorname{LAD}\left(x_{i}\right) f_{e}, s_{\tilde{c}}=$ $\operatorname{LAD}\left(x_{i}\right) f_{c}$, where the leaf-level $f_{e} \approx g D$ and $f_{c}$ may be computed by equations (19) and (21). Because equation (32) solves for the atmospheric $\mathrm{CO}_{2}$ and water vapor concentration, changes in leaf-level fluxes impact these scalar concentrations and $D$ in the atmosphere, which in turn modify $f_{e}$ and $f_{c}$.

[40] To permit implementation of a functional LES in heterogeneous landscapes it is necessary to select an appropriate closure model for the SGS stress and scalar fluxes. For the atmospheric transport of water vapor and carbon dioxide, this model must properly represent the small scale turbulent motions, including leaf-scale processes, while remaining faithful to variable land surface boundary and canopy conditions. Focusing on momentum transport as a case study for a SGS, a mixing length approach (the so-called eddy viscosity model) was proposed, where the unresolved subgrid scale stress, $\tau_{i j}$, is set proportional to the strain rate tensor $\tilde{S}_{i j}$ [Smagorinsky, 1963],

$$
\tilde{S}_{i j}=\frac{1}{2}\left(\partial_{i} \tilde{u}_{j}+\partial_{j} \tilde{u}_{i}\right) ; \quad \tau_{i j}=-2 \nu_{T} \tilde{S}_{i j}
$$

The constant of proportionality is the so-called eddy viscosity $\left(\nu_{T}\right)$, which is written as $\nu_{T}=\lambda_{\text {sg }}|\tilde{S}|$, where $|\tilde{S}|=\left(2 S_{i j} S_{i j}\right)^{1 / 2}$ and $\lambda_{\mathrm{sg}}$ is a mixing length scale. Dimensionally, it follows that $\lambda_{\mathrm{sg}}=c_{s} \Delta$, where $c_{s}$ is a dimensionless model parameter. This parameter must be specified in LES and has received much attention [Meneveau and Katz, 2000; Piomelli, 1999].

[41] Over the past decade, the Smagorinsky model (equation (33)), which is the basis for most LES work on the ABL [Albertson and Parlange, 1999; Moeng, 1984; Shaw and Schumann, 1992], has been studied experimentally over a variety of surfaces using a network of sonic 
anemometers (see Figure 6) for open fields [Porté-Agel et al., 2001], deserts [Higgins et al., 2009], oceans [Kelly et al., 2009], glaciers [Bou-Zeid et al., 2010], and forests [Patton et al., 2011]. The principle behind these field measurements is that the arrays of anemometers discretely sample "sheets" of wind. A sample time series, a sheet of wind in relation to the anemometers, from the SGS 2002 field campaign (deserts in Utah) is presented in Figure 6. The resulting data can be spatially filtered allowing the computation of SGS terms and their modeled counterparts. The resolved turbulent scales are evident as high correlation between the upper and lower sonic arrays with respect to stream-wise velocity (Figures 6a and 6b), and high correlation between upward fluid motions (Figure 6c) and associated increases in local temperatures (Figure 6d). A priori comparisons of the measured SGS stress tensor and the Smagorinsky model estimate produce unsatisfactory results; however, if the experimental comparison is made on the divergence of the stresses (the term that directly enters into the LES equations), good agreement between experiment and model is achieved [Higgins et al., 2009], provided a proper constant of proportionality is chosen (i.e., $c_{s}$ is well characterized). The mathematical foundation to compute $c_{s}$ dynamically within a simulation using the resolved turbulent motions has already been provided [Germano et al., 1991]. This contribution is a substantial advancement in computational fluid mechanics for two reasons: (1) it eliminates all "tunable" parameters from LES, thereby making this approach physically based, and (2) $c_{S}$ is allowed to vary as a function of space and time, which permits the SGS model to respond to the underlying land surface variability. This approach was later improved and extended [Bou-Zeid et al., 2005; Porté-Agel et al., 2000] to incorporate a wider range of scales and Lagrangian path averaging. Several experiments employed this approach [Vercauteren et al., 2009] to reconstruct the behavior of the turbulent Prandtl number over a wide range of atmospheric stabilities, and demonstrated a behavior that is reproducible by the dynamic SGS approach.

[42] These advancements in SGS modeling, when combined with leaf area density mapping methods (e.g., terrestrial laser scanning), allow high-resolution modeling of the flow and water vapor transport in realistic heterogeneous environments. In particular, LES has been used to study correlated land surface variations in leaf area density fields [Albertson et al., 2001], forest edges and sharp transitions [Cassiani et al., 2008], complex topography [Patton and Katul, 2009; Wood, 2000], microscale structural variations within canopies [Bohrer et al., 2009], and temporal transitions resulting from the diurnal cycle [Kumar et al., 2006]. A recent effort to link the microstructural details of the canopy leaf area, as measured by a canopy LiDAR, with LES prepared the field for rapid progress [Schlegel et al., 2012], conditioned on development of realistic SGSs for flows inside canopies. Experiments similar to those reported in Figure 6, but for flows inside canopies, to derive and test SGS formulations have been conducted [Patton et al., 2011]. Large field campaigns were also carried out to compare computed and measured LES surface fluxes [Beyrich and
Mengelkamp, 2006], and many studies investigated the use of LES for determining cloud formation and precipitation [Kogan et al., 1995; Skyllingstad and Edson, 2009; Ackerman et al., 2009]. Hence, with continuously increasing computational capacity and advances in SGS models, usage of LES for water vapor and other scalar transport in the atmospheric boundary layer is rapidly developing and expanding to new fields of research.

\section{CONCLUSIONS AND RECOMMENDATIONS}

[43] The role of ET in the global, terrestrial, and local water cycle was reviewed. At the global scale, it was shown that perturbations in precipitation $(P)$ induced by increases in global air temperature are balanced by perturbations in ET and that these perturbations may be decomposed into two components: a thermodynamic component and a dynamic component. When results from climate models were analyzed for a future climate characterized by an elevated global air temperature $\left(\delta T_{a}\right)$, the thermodynamic component contributed to an "acceleration" in the hydrologic cycle at a rate commensurate with the Clausius-Clapeyron (CC) equation $\left(\delta P / P \approx 6.5 \%{ }^{\circ} \mathrm{C}^{-1}\right)$. On the other hand, the dynamic component regulating mass exchange between the boundary layer and the free troposphere appears to be decelerating the global hydrologic cycle at a rate of about $50 \%$ of $\mathrm{CC}(\delta P / P \approx$ $3 \%{ }^{\circ} \mathrm{C}^{-1}$ ), when $\delta T_{a} / T_{a}$ remains small. Given that this dynamic component is linked to a mass exchange, a logical question to pursue is whether such a globally reduced dynamic mass exchange fingerprints possible reductions in global water vapor circulation. This topic is already being addressed in some climate models, although these investigations could benefit from direct experimental evidence (especially in tropical regions). At the continental scales and for long durations, runoff $\left(R_{o}\right)$ becomes a major hydrologic flux that leads to an imbalance between ET and $P$. Large increases in $R_{o}$ have been reported over the past 100 years, although the reasons for this increase remain contentious. Modeled increases in $P$ over the land surface appear insufficient to explain all the increases in $R_{o}$. This led some investigators to argue that ET over land must have declined over the past 100 years, which is contrary to expectations from global-scale analysis. The hypotheses that have been proposed for a decreasing terrestrial ET over the past 50 100 years have been reviewed (especially the stomatal downregulation under elevated atmospheric $\mathrm{CO}_{2}$ ) and some of their limitations exposed in light of recent experiments (e.g., FACE). Another hypothesis, also discussed here, argues that terrestrial ET is actually increasing, consistent in sign with the global ET. A globally reduced pan evaporation trend along with the complementary hypothesis provides some support for an increased terrestrial ET over the past 50-100 years. If so, then increases in $R_{o}$ must be attributed to other causes (e.g., exploitation of groundwater resulting in increased runoff, increases in permafrost melting, or land use change) that should be considered. Limitations of the pan evaporation record, especially its sensitivity to local micrometeorological conditions (e.g., mean wind field), were also briefly reviewed. 
[44] These findings motivated studies on the effects of elevated atmospheric $\mathrm{CO}_{2}$, increased air temperature, and soil moisture stress on leaf-level transpiration and upscaled canopy-level transpiration. The proposed upscaling resolves all two-way interactions between the leaf and its microclimate. However, describing water flow from the soil through plants into the atmosphere remains a formidable scientific challenge given the high dimensionality and degree of nonlinearity of the soil-plant-atmosphere system. Although rigorous microscopic laws for a coherent representative elementary volume across the soil-plant-atmosphere system still await development, progress has been by developing macroscopic theories. The review covered (1) the economics of leaf gas exchange for describing optimal stomatal aperture in an environment subject to fluctuating vapor pressure deficit, atmospheric $\mathrm{CO}_{2}$, and soil moisture stress, (2) cohesion-tension theory for flow of water in plant xylem and the onset of embolism, (3) Darcy's law and a twodimensional Richard's equation modified to include root water uptake and root-soil permeability for soil moisture redistribution, and (4) simplified turbulence closure schemes for the spatially averaged Navier-Stokes equation describing momentum transport in the canopy-atmosphere system. Land cover fragmentation is already a ubiquitous feature of most landscapes and is predicted to increase, meaning that novel computational methods that go beyond those closure schemes are required - at least for the atmospheric transport components responsible for initiating or triggering rainfall. Given the rapid advancements in satellite based cloud measurements and in ground-based platforms that can map canopy structural properties at unprecedented resolution, the review shows that LES offer a logical bridge between these classes of measurements provided subgrid scale fluxes are adequately represented. The review presents recent progress in experiments and subgrid scale modeling intended to enable large eddy simulations to tackle such complex problems.

\section{NOTATION}

a relative diffusivity of water vapor with respect to carbon dioxide $(=1.6)$.

$a_{\mathrm{cc}}$ constant in the $\mathrm{CC}$ equation $(=0.611 \mathrm{kPa})$.

$a_{1}$ constant in equation (12) related to the biochemical demand function.

$a_{2}$ constant in equation (12) related to the biochemical demand function.

ABL atmospheric boundary layer.

AP stomatal aperture.

$b$ constant in the Clausius-Clapeyron equation $\left(=17.5^{\circ} \mathrm{C}^{-1}\right)$.

$c$ constant in the Clausius-Clapeyron equation $\left(=249.93^{\circ} \mathrm{C}\right)$.

$C$ water vapor concentration.

$c_{a}$ ambient $\mathrm{CO}_{2}$ concentration.

$\mathrm{CC}$ Clausius-Clapeyron equation (equation (3)).

$c_{i}$ intercellular $\mathrm{CO}_{2}$ concentration.

$c_{o}$ reference atmospheric $\mathrm{CO}_{2}$ concentration $=$ $380 \mathrm{ppm}$. $c_{p} \quad \mathrm{CO}_{2}$ compensation point.

$c_{s} \quad$ Smagorinsky constant.

CT cohesion-tension.

$D$ vapor pressure deficit.

$e^{*} \quad$ saturation vapor pressure at a given temperature (given by $\mathrm{CC}$ ).

$e_{a}$ ambient vapor pressure.

$e_{i} \quad$ intercellular vapor pressure.

ET evapotranspiration.

FACE Free Air $\mathrm{CO}_{2}$ Enrichment.

$f_{e}$ leaf-scale transpiration.

$f_{c}$ leaf-scale $\mathrm{CO}_{2}$ flux.

$F_{l i}(\mathrm{~g})$ objective function relating $\mathrm{CO}_{2}$ uptake and water loss for a linearized biochemical demand function.

$F_{n l}(\mathrm{~g})$ objective function relating $\mathrm{CO}_{2}$ uptake and water loss for the general biochemical demand function. leaf-scale conductance to $\mathrm{CO}_{2}$. acceleration due to gravity. root-leaf conductance. soil-root conductance. global conductance to water vapor.

estimated for terrestrial areas.

HR hydraulic redistribution.

$K_{e} \quad$ eddy diffusivity for scalars.

$K_{r} \quad$ interfacial hydraulic properties at the soil-root interface.

$\operatorname{LAD}(z)$ layer-wise leaf area density.

LAI leaf area index.

LES large eddy simulation.

LCL lifting condensation level.

$M$ mass of water vapor exchanged between the boundary layer and the free troposphere per unit time.

$m_{\mathrm{BB}} \quad$ sensitivity parameter of the Ball-Berry stomatal conductance model.

$m_{\text {LEU }}$ sensitivity parameter of the Leuning stomatal conductance model.

OF abandoned agricultural field.

$n_{a}$ number of molecules in the air column above the surface.

$P$ precipitation.

$P_{a}$ air pressure.

$\tilde{p} \quad$ filtered atmospheric pressure field.

RH air relative humidity.

$R_{o} \quad$ cumulative continental scale runoff.

$s$ long-term intercellular to ambient $\mathrm{CO}_{2}$ concentration ratio $\left(c_{i} / c_{a}\right)$.

$S_{c}$ planar-averaged sources of water vapor.

$s_{\tilde{c}} \quad$ localized source of $\mathrm{CO}_{2}$.

$s_{\tilde{q}} \quad$ localized source of water vapor.

$s_{\tilde{\theta}} \quad$ localized source of heat.

SD stomatal density.

$S_{i j}$ strain rate tensor.

SGS subgrid scale. 


\author{
$T_{a}$ air temperature. \\ $T_{r}$ canopy transpiration rate. \\ $\tilde{u}_{i} \quad$ filtered velocity vector. \\ $V_{a}$ volume of air in the column above a land \\ surface per unit area. \\ $\overline{w^{\prime} C^{\prime}}$ turbulent flux of water vapor. \\ WUE water use efficiency. \\ $\alpha \quad$ inefficiency of the hydrological cycle. \\ $\alpha_{T}$ thermal diffusivity. \\ $\beta_{o}$ slope parameter. \\ $\Delta$ grid scale. \\ $\delta_{i j} \quad$ Kronecker delta. \\ $\tilde{\theta} \quad$ filtered air temperature. \\ $\lambda$ marginal water use efficiency. \\ $\lambda_{o}$ marginal water use efficiency at a reference \\ $\mathrm{CO}_{2}$ concentration $c_{o}$. \\ $\lambda_{s g} \quad$ mixing length scale of eddies. \\ $\lambda_{\mathrm{ww}}$ marginal water use efficiency in well-watered \\ conditions. \\ $\nu_{T} \quad$ eddy viscosity. \\ $\pi_{j}^{\tilde{c}} \quad$ subgrid scale flux of $\mathrm{CO}_{2}$. \\ $\pi_{j}^{\tilde{q}} \quad$ subgrid scale flux of water vapor. \\ $\pi_{j}^{\tilde{\theta}} \quad$ subgrid scale flux of heat. \\ $\rho, \rho_{w} \quad$ mean density of air and liquid water, \\ respectively. \\ $\tau_{i j} \quad$ subgrid scale stress. \\ $\psi_{S}, \psi_{R}, \psi_{L} \quad$ soil, root, and leaf water potentials, \\ respectively.
}

[45] ACKNOWLEDGMENTS. Support from the National Science Foundation (NSF EAR-1013339, NSF CBET-1033467, and NSF-AGS-110227), the United States Department of Agriculture (2011-67003-30222), and the United States Department of Energy (DOE) through the Office of Biological and Environmental Research (BER) Terrestrial Carbon Processes (TCP) program (FACE and NICCR grants: DE-FG02-95ER62083, DE-FC02-06ER64156) and through the Terrestrial Ecosystem Science (TES) program (DE-SC0006967) are acknowledged. The authors thank A. Konings and S. Thompson for all their comments and suggestions.

[46] The Editor on this paper was Greg Okin. He thanks the Associate Editor, M. Bayani Cardenas, and two anonymous reviewers.

\section{REFERENCES}

Ackerman, A. S., et al. (2009), Large eddy simulations of a drizzling, stratocumulus-topped marine boundary layer, Mon. Weather Rev., 137, 1083-1110, doi:10.1175/2008MWR2582.1.

Adler, R. F., et al. (2008), Relationships between global precipitation and surface temperature on interannual and longer timescales (1979-2006), J. Geophys. Res., 113, D22104, doi:10.1029/ 2008JD010536.

Ainsworth, E. A., and A. Rogers (2007), The response of photosynthesis and stomatal conductance to rising $\left[\mathrm{CO}_{2}\right]$ : Mechanisms and environmental interactions, Plant Cell Environ., 30, 258-270, doi:10.1111/j.1365-3040.2007.01641.x.

Albertson, J. D., and M. B. Parlange (1999), Natural integration of scalar fluxes from complex terrain, Adv. Water Resour., 23, 239-252, doi:10.1016/S0309-1708(99)00011-1.
Albertson, J. D., et al. (2001), Relative importance of local and regional controls on coupled water, carbon, and energy fluxes, Adv. Water Resour., 24(9-10), 1103-1118, doi:10.1016/S03091708(01)00042-2.

Allen, M. R., and W. J. Ingram (2002), Constraints on future changes in climate and the hydrologic cycle, Nature, 419(6903), 224-232, doi:10.1038/nature01092.

Allen, R. G., and W. O. Pruitt (1986), Rational use of the FAO Blaney-Criddle formula, J. Irrig. Drain. Eng., 112, 139-155, doi:10.1061/(ASCE)0733-9437(1986)112:2(139).

Alpert, P., et al. (2005), Global dimming or local dimming?: Effect of urbanization on sunlight availability, Geophys. Res. Lett., 32, L17802, doi:10.1029/2005GL023320.

Anderson, L., et al. (2001), Gas exchange and photosynthetic acclimation over subambient to elevated $\mathrm{CO}_{2}$ in a C-3-C-4 grassland, Global Change Biol., 7, 693-707, doi:10.1046/j.1354-1013. 2001.00438.x.

Andre, J. C., et al. (1986), HAPEX-MOBILHY: A hydrologicatmospheric experiment for the study of water budget and evaporation flux at the climatic scale, Bull. Am. Meteorol. Soc., 67(2), 138-144, doi:10.1175/1520-0477(1986)067<0138:HAHAEF> 2.0.CO;2.

Angeles, G., et al. (2004), The Cohesion-Tension theory, New Phytol., 163(3), 451-452, doi:10.1111/j.1469-8137.2004.01142.x.

Avissar, R., et al. (2002), The Large-Scale Biosphere-Atmosphere Experiment in Amazonia (LBA), J. Geophys. Res., 107(D20), 8086, doi:10.1029/2002JD002704.

Baldocchi, D., and T. Meyers (1998), On using eco-physiological, micrometeorological and biogeochemical theory to evaluate carbon dioxide, water vapor and trace gas fluxes over vegetation: A perspective, Agric. For. Meteorol., 90, 1-25, doi:10.1016/ S0168-1923(97)00072-5.

Baldocchi, D., et al. (2001), FLUXNET: A new tool to study the temporal and spatial variability of ecosystem-scale carbon dioxide, water vapor, and energy flux densities, Bull. Am. Meteorol. Soc., 82(11), 2415-2434, doi:10.1175/1520-0477 (2001)082<2415:FANTTS $>2.3$. CO $;$.

Betts, R. A., et al. (2007), Projected increase in continental runoff due to plant responses to increasing carbon dioxide, Nature, 448, 1037-1041, doi:10.1038/nature06045.

Beyrich, F., and H. T. Mengelkamp (2006), Evaporation over a heterogeneous land surface: EVA-GRIPS and the LITFASS2003 experiment-An overview, Boundary Layer Meteorol., 121, 5-32, doi:10.1007/s10546-006-9079-z.

Bohrer, G., et al. (2005), Finite element tree crown hydrodynamics model (FETCH) using porous media flow within branching elements: A new representation of tree hydrodynamics, Water Resour. Res., 41, W11404, doi:10.1029/2005WR004181.

Bohrer, G., et al. (2009), Exploring the effects of microscale structural heterogeneity of forest canopies using Large-Eddy Simulations, Boundary Layer Meteorol., 132, 351-382, doi:10.1007/ s10546-009-9404-4.

Bonner, J. (1959), Water transport, Science, 129(3347), 447-450, doi:10.1126/science.129.3347.447.

Borchert, R. (1994), Soil and stem water storage determine phenology and distribution of tropical dry forest trees, Ecology, 75, 1437-1449, doi:10.2307/1937467.

Bou-Zeid, E., et al. (2005), A scale-dependent Lagrangian dynamic model for large eddy simulation of complex turbulent flows, Phys. Fluids, 17, 025105, doi:10.1063/1.1839152.

Bou-Zeid, E., et al. (2010), Field study of the dynamics and modelling of subgrid-scale turbulence in a stable atmospheric surface layer over a glacier, J. Fluid Mech., 665, 480-515, doi:10.1017/ S0022112010004015.

Bowen, I. S. (1926), The ratio of heat losses by conduction and by evaporation from any water surface, Phys. Rev., 27(6), 779-787, doi:10.1103/PhysRev.27.779. 
Brutsaert, W. B. (1982), Evaporation Into the Atmosphere: Theory, History, and Applications, Kluwer Acad., Dordrecht, Netherlands.

Brutsaert, W. B. (2006), Indications of increasing land surface evaporation during the second half of the 20th century, Geophys. Res. Lett., 33, L20403, doi:10.1029/2006GL027532.

Brutsaert, W. B., and M. B. Parlange (1998), Hydrologic cycle explains the evaporation paradox, Nature, 396(6706), 30-31, doi:10.1038/23845.

Brutsaert, W. B., and H. Stricker (1979), An advection-aridity approach to estimate actual regional evapotranspiration, Water Resour. Res., 15, 443-449, doi:10.1029/WR015i002p00443.

Buckley, T. N., et al. (2003), A hydromechanical and biochemical model of stomatal conductance, Plant Cell Environ., 26(10), 1767-1785, doi:10.1046/j.1365-3040.2003.01094.x.

Budyko, M. (1974), Climate and Life, Academic, New York.

Caldwell, M. M., et al. (1998), Hydraulic lift: Consequences of water efflux from the roots of plants, Oecologia, 113, 151-161, doi: $10.1007 / \mathrm{s} 004420050363$.

Campbell, G. S., and J. M. Norman (1998), An Introduction to Environmental Biophysics, 2nd ed., 286 pp., Springer, New York, doi:10.1007/978-1-4612-1626-1.

Cassiani, M., et al. (2008), The effects of canopy leaf area index on airflow across forest edges: Large-eddy simulation and analytical results, Boundary Layer Meteorol., 126, 433-460, doi:10.1007/ s10546-007-9242-1.

Chuang, Y. L., R. Oren, A. L. Bertozzi, N. Phillips, and G. G. Katul (2006), The porous media model for the hydraulic system of a conifer tree: Linking sap flux data to transpiration rate, Ecol. Modell., 191, 447-468, doi:10.1016/j.ecolmodel.2005.03.027.

Collatz, G. J., et al. (1991), Physiological and environmental regulations of stomatal conductance, photosynthesis and transpiration: A model that includes a laminar boundary-layer, Agric. For. Meteorol., 54(2-4), 107-136, doi:10.1016/0168-1923(91) 90002-8.

Corcuera, L., et al. (2011), Phenotypic plasticity in mesic populations of Pinus pinaster improves resistance to xylem embolism $\left(\mathrm{P}_{50}\right)$ under severe drought, Trees Struct. Funct., 25, 1033-1042, doi:10.1007/s00468-011-0578-2.

Cowan, I. R. (1986), Economics of carbon fixation in higher plants, in On the Economy of Plant Form and Function, edited by T. J. Givnish, pp. 133-170, Cambridge Univ. Press, Cambridge, U. K.

Cowan, I. R., and G. D. Farquhar (1977), Stomatal function in relation to leaf metabolism and environment, in Integration of Activity in the Higher Plant, edited by D. H. Jehnnings, pp. 471-505, Cambridge Univ. Press, Cambridge, U. K.

Cruiziat, P., H. Cochard, and T. Ameglio (2002), Hydraulic architecture of trees: Main concepts and results, Ann. For. Sci., 59 , 723-752, doi:10.1051/forest:2002060.

Dai, A., et al. (1999), Effects of clouds, soil moisture, precipitation, and water vapor on diurnal temperature range, J. Clim., 12(8), 2451-2473, doi:10.1175/1520-0442(1999)012<2451:EOCSMP $>2$. $0 . \mathrm{CO} ; 2$.

Dai, A. I., Y. Fung, and A. D. Del Genio (1997), Surface observed global land precipitation variations during 1900-88. J. Clim., 10, 2943-2962.

Daly, E., A. Porporato, and I. Rodriguez-Iturbe (2004), Coupled dynamics of photosynthesis, transpiration, and soil water balance. Part I: Upscaling from hourly to daily level, J. Hydrometeorol., 5, 546-558, doi:10.1175/1525-7541(2004)005<0546:CDOPTA $>2$. $0 . \mathrm{CO} ; 2$.

Damour, G., et al. (2010), An overview of models of stomatal conductance at the leaf level, Plant Cell Environ., 33(9), 1419-1438.

Darwin, F. (1898), Observations on stomata, Proc. R. Soc. London, 63, 413-417, doi:10.1098/rspl.1898.0053.

DeLucia, E. H., and S. A. Heckathorn (1989), The effect of soil drought on water-use efficiency in a contrasting Great-Basin desert and Sierran montane species, Plant Cell Environ., 12, 935-940, doi:10.1111/j.1365-3040.1989.tb01973.x.
Dewar, R. C. (2002), The Ball-Berry-Leuning and Tardieu-Davies stomatal models: Synthesis and extension within a spatially aggregated picture of guard cell function, Plant Cell Environ., 25, 1383-1398, doi:10.1046/j.1365-3040.2002.00909.x.

Dirmeyer, P. A., and K. L. Brubaker (2006), Evidence for trends in the Northern Hemisphere water cycle, Geophys. Res. Lett., 33, L14712, doi:10.1029/2006GL026359.

Dixon, H. (1914), Transpiration and the Ascent of Sap in Plants, 216 pp., Macmillian, New York, doi:10.5962/bhl.title.1943.

Domec, J. C., et al. (2009), Acclimation of leaf hydraulic conductance and stomatal conductance of Pinus taeda (loblolly pine) to long-term growth in elevated $\mathrm{CO} 2$ (free-air $\mathrm{CO} 2$ enrichment) and N-fertilization, Plant Cell Environ., 32(11), 1500-1512, doi:10.1111/j.1365-3040.2009.02014.x.

Domec, J. C., et al. (2010), Hydraulic redistribution of soil water by roots affects whole-stand evapotranspiration and net ecosystem carbon exchange, New Phytol., 187(1), 171-183, doi:10.1111/ j.1469-8137.2010.03245.x.

Eamus, D., and L. Prior (2001), Ecophysiology of trees of seasonally dry tropics: Comparisons among phenologies, Adv. Ecol. Res, 32, 113-197, doi:10.1016/S0065-2504(01)32012-3.

Ellsworth, D. S., et al. (1995), Leaf and canopy responses to elevated $\mathrm{CO}_{2}$ in a pine forest under Free Air $\mathrm{CO}_{2}$ Enrichment, Oecologia, 104(2), 139-146, doi:10.1007/BF00328578.

Emerman, S. H., and T. E. Dawson (1996), Hydraulic lift and its influence on the water content of the rhizosphere: An example from sugar maple, Acer saccharum, Oecologia, 108(2), 273-278.

Ewers, B. E., R. Oren, and J. S. Sperry (2000), Influence of nutrient versus water supply on hydraulic architecture and water balance in Pinus taeda, Plant Cell Environ., 23, 1055-1066, doi:10.1046/ j.1365-3040.2000.00625.x.

Farquhar, G. D., et al. (1980), A biochemical model of photosynthetic $\mathrm{CO}_{2}$ assimilation in leaves of $\mathrm{C}_{3}$ species, Planta, 149(1), 78-90, doi:10.1007/BF00386231.

Fay, P. A., A. M. Kelley, A. C. Procter, D. Hui, V. L. Jin, R. B. Jackson, H. B. Johnson, and H. W. Polley (2009), Primary productivity and water balance of grassland vegetation on three soils in a continuous $\mathrm{CO}_{2}$ gradient: Initial results from the Lysimeter $\mathrm{CO}_{2}$ Gradient Experiment, Ecosystems NY, 12, 699-714, doi:10.1007/s10021-009-9247-3.

Field, C. B., et al. (1995), Stomatal responses to increased CO2: Implications from the plant to the global scale, Plant Cell Environ., 18(10), 1214-1225, doi:10.1111/j.1365-3040.1995. tb00630.x.

Finnigan, J. J. (2000), Turbulence in plant canopies, Annu. Rev. Fluid Mech., 32, 519-571, doi:10.1146/annurev.fluid.32.1.519.

Garratt, J. R. (1992), The Atmospheric Boundary Layer, Cambridge Univ. Press, New York.

Gedney, N., P. M. Cox, R. A. Betts, O. Boucher, C. Huntingford, and P. A. Stott (2006), Detection of a direct carbon dioxide effect in continental river runoff records, Nature, 439, 835-838, doi:10.1038/nature04504.

Germano, M., et al. (1991), A dynamic subgrid scale eddy viscosity model, Phys. Fluids, 3, 1760-1765.

Giorgi, F., and R. Avissar (1997), Representation of heterogeneity effects in Earth system modeling: Experience from land surface modeling, Rev. Geophys., 35(4), 413-437, doi:10.1029/ 97RG01754.

Givnish, T. J., and G. J. Vermeij (1976), Sizes and shapes of Liane leaves, Am. Nat., 110(975), 743-778, doi:10.1086/283101.

Gleick, P. H. (1989), Climate change, hydrology, and water resources, Rev. Geophys., 27(3), 329-344, doi:10.1029/ RG027i003p00329.

Golubev, V. S., et al. (2001), Evaporation changes over the contiguous United States and the former USSR: A reassessment, Geophys. Res. Lett., 28, 2665-2668, doi:10.1029/2000GL012851.

Goutorbe, J. P., et al. (1994), HAPEX-SAHEL: A large scale study of land-atmosphere interactions in the semi-arid tropics, Ann. Geophys., 12(1), 53-64. 
Granger, R. J. (1989), A complementary relationship approach for evaporation from nonsaturated surfaces, J. Hydrol., 111, 31-38, doi:10.1016/0022-1694(89)90250-3.

Groisman, P. Y., et al. (2004), Contemporary changes of the hydrological cycle over the contiguous United States: Trends derived from in situ observations, J. Hydrometeorol., 5, 64-85, doi:10.1175/1525-7541(2004)005<0064:CCOTHC $>2.0$.CO;2.

Guswa, A. J. (2010), Effect of plant uptake strategy on the water-optimal root depth, Water Resour. Res., 46, W09601, doi:10.1029/2010WR009122.

Hacke, U. G., et al. (2000), Influence of soil porosity on water use in Pinus taeda, Oecologia, 124, 495-505, doi:10.1007/PL00008875.

Hacke, U. G., et al. (2001), Trends in wood density and structure are linked to prevention of xylem implosion by negative pressure, Oecologia, 126, 457-461, doi:10.1007/s004420100628.

Hacke, U. G., et al. (2006), Scaling of angiosperm xylem structure with safety and efficiency, Tree Physiol., 26, 689-701, doi:10.1093/treephys/26.6.689.

Hari, P., et al. (1986), Optimal control of gas exchange, Tree Physiol., 2(1-3), 169-175.

Held, I. M., and B. J. Soden (2006), Robust responses of the hydrological cycle to global warming, J. Clim., 19(21), 5686-5699, doi:10.1175/JCLI3990.1.

Higgins, C. W., et al. (2009), Geometric alignments of the subgridscale force in the atmospheric boundary layer, Boundary Layer Meteorol., 132, 1-9, doi:10.1007/s10546-009-9385-3.

Hobbins, M. T., et al. (2004), Trends in pan evaporation and actual evaporation across the conterminous U.S.: Paradoxical or complementary?, Geophys. Res. Lett., 31, L13503, doi:10.1029/ 2004GL019846.

Horton, J. L., and S. C. Hart (1998), Hydraulic lift: A potentially important ecosystem process, Trends Ecol. Evol., 13, 232-235, doi:10.1016/S0169-5347(98)01328-7.

Hoyt, W. G., and W. B. Langbein (1939), Some general observations of physiographic and climatic influences on floods, Eos Trans. $A G U, 20,166-174$

Hsiao, T. C. (1973), Plant response to water stress, Annu. Rev. Plant Physiol. Plant Mol. Biol., 24, 519-570, doi:10.1146/ annurev.pp.24.060173.002511.

Hulme, M., et al. (1998), Precipitation sensitivity to global warming: Comparison of observations with HadCM2 simulations, Geophys. Res. Lett., 25(17), 3379-3382, doi:10.1029/ 98GL02562.

Huntington, T. G. (2006), Evidence for intensification of the global water cycle: Review and synthesis, J. Hydrol., 319(1-4), 83-95, doi:10.1016/j.jhydrol.2005.07.003.

Huntington, T. G. (2010), Climate warming-induced intensification of the hydrologic cycle: An assessment of the published record and potential impacts on agriculture, Adv. Agron., 109, 1-53, doi:10.1016/B978-0-12-385040-9.00001-3.

Idso, S. B., and A. J. Brazel (1984), Rising atmospheric carbon dioxide concentrations may increase streamflow, Nature, 312(5989), 51-53, doi:10.1038/312051a0.

Jackson, R. B., et al. (2005), Trading water for carbon with biological sequestration, Science, 310(5756), 1944-1947, doi:10.1126/ science. 1119282

Jarvis, P. G. (1976), Interpretation of variations in leaf water potential and stomatal conductance found in canopies in field, Philos. Trans. R. Soc. London, Ser. B, 273(927), 593-610, doi:10.1098/rstb.1976.0035.

Jarvis, P. G., and K. G. McNaughton (1986), Stomatal control of transpiration - scaling up from leaf to region, $A d v$. Ecol. Res, 15, 1-49, doi:10.1016/S0065-2504(08)60119-1.

Jones, H. G. (1992), Plants and Microclimate. A Quantitative Approach to Environmental Plant Physiology, Cambridge Univ. Press, Cambridge, U. K.

Juang, J. Y., et al. (2007a), Eco-hydrological controls on summertime convective rainfall triggers, Global Change Biol., 13(4), 887-896, doi:10.1111/j.1365-2486.2007.01315.x.
Juang, J. Y., et al. (2007b), Hydrologic and atmospheric controls on initiation of convective precipitation events, Water Resour. Res., 43, W03421, doi:10.1029/2006WR004954.

Juang, J. Y., et al. (2008), Investigating a hierarchy of Eulerian closure models for scalar transfer inside forested canopies, Boundary Layer Meteorol., 128(1), 1-32, doi:10.1007/s10546008-9273-2.

Jung, M., et al. (2010), Recent decline in the global land evapotranspiration trend due to limited moisture supply, Nature, 467(7318), 951-954, doi:10.1038/nature09396.

Kahler, D. M., and W. Brutsaert (2006), Complementary relationship between daily evaporation in the environment and pan evaporation, Water Resour. Res., 42, W05413, doi:10.1029/ 2005WR004541.

Karl, T. R., and R. W. Knight (1998), Secular trends of precipitation amount, frequency, and intensity in the United States. Bull. Am. Meteorol. Soc., 79, 231-241.

Karl, T. R., R. W. Knight, D. R. Easterling, and R. G. Quayle (1996), Indices of climate change for the United States, Bull. Am. Meteorol. Soc., 77, 279-292.

Katul, G. G., and K. A. Novick (2009), Evapotranspiration, in Encyclopedia of Inland Waters, edited by G. E. Likens, pp. 661-667, Elsevier, Oxford, U. K., doi:10.1016/B978012370626-3.00012-0.

Katul, G. G., S. Palmroth, and R. Oren (2009), Leaf stomatal responses to vapour pressure deficit under current and $\mathrm{CO}_{2-}$ enriched atmosphere explained by the economics of gas exchange, Plant Cell Environ., 32, 968-979, doi:10.1111/ j.1365-3040.2009.01977.x.

Katul, G. G., et al. (2010), A stomatal optimization theory to describe the effects of atmospheric $\mathrm{CO}_{2}$ on leaf photosynthesis and transpiration, Ann. Bot., 105(3), 431-442, doi:10.1093/aob/ mcp292.

Kelly, M., et al. (2009), Application of a subfilter scale flux model over the ocean using OHATS field data, J. Atmos. Sci., 66, 3217-3225, doi:10.1175/2009JAS2903.1.

Kogan, Y. 1., et al. (1995), Modeling of stratocumulus cloud layers in a large eddy simulation-model with explicit microphysics, J. Atmos. Sci., 52, 2923-2940, doi:10.1175/1520-0469(1995) 052<2923:MOSCLI >2.0.CO;2.

Kolb, K. J., and J. S. Sperry (1999), Transport constraints on water use by the Great Basin shrub, Artemisia tridentata, Plant Cell Environ., 22, 925-935, doi:10.1046/j.1365-3040.1999.00458.x.

Konings, A. G., et al. (2010), The rainfall-no rainfall transition in a coupled land-convective atmosphere system, Geophys. Res. Lett., 37, L14401, doi:10.1029/2010GL043967.

Kumar, V., et al. (2006), Large-eddy simulation of a diurnal cycle of the atmospheric boundary layer: Atmospheric stability and scaling issues, Water Resour. Res., 42, W06D09, doi:10.1029/ 2005WR004651.

Labat, D., et al. (2004), Evidence for global runoff increase related to climate warming, Adv. Water Resour., 27(6), 631-642, doi:10.1016/j.advwatres.2004.02.020.

Laio, F., et al. (2001), Plants in water-controlled ecosystems: Active role in hydrologic processes and response to water stress - II. Probabilistic soil moisture dynamics, Adv. Water Resour., 24, 707-723, doi:10.1016/S0309-1708(01)00005-7.

Langbein, W. B. (1949), Annual runoff in the United States, U.S. Geol. Surv. Circ., 52, 14 pp.

Launiainen, S., et al. (2011), Empirical and optimal stomatal controls on leaf and ecosystem level $\mathrm{CO}_{2}$ and $\mathrm{H}_{2} \mathrm{O}$ exchange rates, Agric. For. Meteorol., 151, 1672-1689, doi:10.1016/j.agrformet. 2011.07.001.

Laurance, W. (2004), Forest-climate interactions in fragmented tropical landscapes, Philos. Trans. R. Soc. London B, 359, 345-352, doi:10.1098/rstb.2003.1430.

Lawlor, D. W., and G. Cornic (2002), Photosynthetic carbon assimilation and associated metabolism in relation to water 
deficits in higher plants, Plant Cell Environ., 25(2), 275-294, doi:10.1046/j.0016-8025.2001.00814.x.

Lawlor, D. W., and W. Tezara (2009), Causes of decreased photosynthetic rate and metabolic capacity in water-deficient leaf cells: A critical evaluation of mechanisms and integration of processes, Ann. Bot., 103(4), 561-579, doi:10.1093/aob/mcn244.

Lawrence, M. G. (2005), The relationship between relative humidity and the dew point temperature in moist air: A simple conversion and applications, Bull. Am. Meteorol. Soc., 86, 225-233, doi:10.1175/BAMS-86-2-225.

Lawrimore, J. H., and T. C. Peterson (2000), Pan evaporation trends in dry and humid regions of the United States, J. Hydrometeorol., 1, 543-546, doi:10.1175/1525-7541(2000)001<0543: PETIDA $>2.0 . \mathrm{CO} ; 2$.

Leuning, R. (1995), A critical appraisal of a combined stomatalphotosynthesis model for C3 plants, Plant Cell Environ., 18(4), 339-355, doi:10.1111/j.1365-3040.1995.tb00370.x.

Liepert, B. G., and M. Previdi (2009), Do models and observations disagree on the rainfall response to global warming?, J. Clim., 22(11), 3156-3166, doi:10.1175/2008JCLI2472.1.

Liu, B., et al. (2004), A spatial analysis of pan evaporation trends in China, 1955-2000, J. Geophys. Res., 109, D15102, doi:10.1029/ 2004JD004511.

Maherali, H., W. T. Pockman, and R. B. Jackson (2004), Adaptive variation in the vulnerability of woody plants to xylem cavitation, Ecology, 85, 2184-2199, doi:10.1890/02-0538.

Mäkelä, A., F. Berninger, and P. Hari (1996), Optimal control of gas exchange during drought: Theoretical analysis, Ann. Bot., 77, 461-468, doi:10.1006/anbo.1996.0056.

Manabe, S., et al. (1965), Simulated climatology of a general circulation model with a hydrologic cycle, Mon. Weather Rev., 93, 769-798, doi:10.1175/1520-0493(1965)093<0769: SCOAGC $>2$ .3.CO;2.

Manabe, S., et al. (2004a), Simulated long-term changes in river discharge and soil moisture due to global warming, Hydrol. Sci. J., 49(4), 625-642, doi:10.1623/hysj.49.4.625.54429.

Manabe, S., et al. (2004b), Century-scale change in water availability: $\mathrm{CO}_{2}$-quadrupling experiment, Clim. Change, 64(1-2), 59-76, doi:10.1023/B:CLIM.0000024674.37725.ca.

Manzoni, S., et al. (2011a), Modeling the vegetation-atmosphere carbon dioxide and water vapor interactions along a controlled $\mathrm{CO}_{2}$ gradient, Ecol. Modell., 222, 653-665, doi:10.1016/j. ecolmodel.2010.10.016.

Manzoni, S., et al. (2011b), Optimizing stomatal conductance for maximum carbon gain under water stress: A meta-analysis across plant functional types and climates, Funct. Ecol., 25(3), 456-467, doi:10.1111/j.1365-2435.2010.01822.x.

Manzoni, S., et al. (2012), Biological constraints on water transport in the soil-plant-atmosphere system, $A d v$. Water Resour., doi:10.1016/j.advwatres.2012.03.016, in press.

Maseda, P. H., and R. J. Fernandez (2006), Stay wet or else: Three ways in which plants can adjust hydraulically to their environment, J. Exp. Bot., 57(15), 3963-3977, doi:10.1093/jxb/erl127.

McCarthy, H. R., et al. (2007), Temporal dynamics and spatial variability in the enhancement of canopy leaf area under elevated atmospheric $\mathrm{CO}_{2}$, Global Change Biol., 13(12), 2479-2497, doi:10.1111/j.1365-2486.2007.01455.x.

McDowell, N., et al. (2008), Mechanisms of plant survival and mortality during drought: Why do some plants survive while others succumb to drought?, New Phytol., 178(4), 719-739, doi:10.1111/j.1469-8137.2008.02436.x.

Medlyn, B. E., et al. (2001), Stomatal conductance of forest species after long-term exposure to elevated $\mathrm{CO} 2$ concentration: A synthesis, New Phytol., 149(2), 247-264, doi:10.1046/j.1469-8137. 2001.00028.x.

Medlyn, B. E., et al. (2011), Reconciling the optimal and empirical approaches to modelling stomatal conductance, Global Change Biol., 17(6), 2134-2144, doi:10.1111/j.1365-2486.2010.02375.x.
Mendel, M., et al. (2002), On a better understanding of hydraulic lift: A numerical study, Water Resour. Res., 38(10), 1183, doi:10.1029/2001WR000911.

Meneveau, C., and J. Katz (2000), Scale invariance and turbulence models for Large-Eddy-Simulation, Annu. Rev. Fluid Mech., 319 , 353-385.

Milly, P. C. D., et al. (2005), Global pattern of trends in streamflow and water availability in a changing climate, Nature, 438(7066), 347-350, doi:10.1038/nature04312.

Moeng, C.-H. (1984), A large-eddy simulation model for the study of planetary boundary-layer turbulence, J. Atmos. Sci., 41, 2052-2062, doi:10.1175/1520-0469(1984)041<2052:ALESMF $>2$. $0 . \mathrm{CO} ; 2$.

Monteith, J. L. (1965), Light distribution and photosynthesis in field crops, Ann. Bot., 29(113), 17-37.

Monteith, J. L. (1995), A reinterpretation of stomatal responses to humidity, Plant Cell Environ., 18, 357-364, doi:10.1111/ j.1365-3040.1995.tb00371.x.

Morton, F. I. (1983), Operational estimates of areal evapotranspiration and their significance to the science and practice of hydrology, J. Hydrol., 66, 1-76, doi:10.1016/0022-1694(83)90177-4.

Negri, A. J., et al. (2004), The impact of Amazonian deforestation on dry season rainfall, J. Clim., 17, 1306-1319, doi:10.1175/ 1520-0442(2004)017<1306:TIOADO >2.0.CO;2.

Novick, K., et al. (2009), The relationship between reference canopy conductance and simplified hydraulic architecture, $A d v$. Water Resour., 32, 809-819, doi:10.1016/j.advwatres.2009. 02.004 .

Ohmura, A., and M. Wild (2002), Is the hydrological cycle accelerating?, Science, 298(5597), 1345-1346, doi:10.1126/science. 1078972.

Oishi, A. C., et al. (2010), Interannual invariability of forest evapotranspiration and its consequence to water flow downstream, Ecosystems, 13(3), 421-436, doi:10.1007/s10021-010-9328-3.

Oki, T., and S. Kanae (2006), Global hydrological cycles and world water resources, Science, 313(5790), 1068-1072, doi:10.1126/ science. 1128845 .

Oliveira, R. S., et al. (2005), Hydraulic redistribution in three Amazonian trees, Oecologia, 145, 354-363, doi:10.1007/ s00442-005-0108-2.

Oren, R., et al. (1999), Survey and synthesis of intra- and interspecific variation in stomatal sensitivity to vapour pressure deficit, Plant Cell Environ., 22, 1515-1526, doi:10.1046/j.1365-3040. 1999.00513.x.

Parlange, M. B., and G. G. Katul (1992), An AdvectionAridity evaporation model, Water Resour. Res., 28, 127-132, doi:10.1029/91WR02482.

Parlange, M. B., et al. (1995), Regional scale evaporation and the atmospheric boundary layer, Rev. Geophys., 33(1), 99-124, doi:10.1029/94RG03112.

Pataki, D. E., et al. (1998), Elevated carbon dioxide does not affect average canopy stomatal conductance of Pinus taeda L, Oecologia, 117(1-2), 47-52, doi:10.1007/s004420050630.

Patton, E. G., and G. G. Katul (2009), Turbulent pressure and velocity perturbations induced by gentle hills covered with sparse and dense canopies, Boundary Layer Meteorol., 133(2), 189-217, doi:10.1007/s10546-009-9427-x.

Patton, E., et al. (2011), The Canopy Horizontal Array Turbulence Study, Bull. Am. Meteorol. Soc., 92, 593-611.

Penman, H. L. (1948), Natural evaporation from open water, bare soil, and grass, Philos. Trans. R. Soc. London B, 193(1032), $120-145$

Peterson, B. J., et al. (2002), Increasing river discharge to the Arctic Ocean, Science, 298, 2171-2173, doi:10.1126/science.1077445.

Peterson, T. C., et al. (1995), Evaporation losing its strength, Nature, 377, 687-688, doi:10.1038/377687b0.

Piao, S. L., et al. (2007), Changes in climate and land use have a larger direct impact than rising $\mathrm{CO} 2$ on global river runoff trends, 
Proc. Natl. Acad. Sci. U. S. A., 104(39), 15,242-15,247, doi:10.1073/pnas.0707213104.

Pielke, R. A. (2001), Influence of the spatial distribution of vegetation and soils on the prediction of cumulus convective rainfall, Rev. Geophys., 39, 151-177, doi:10.1029/1999RG000072.

Pinker, R. T., et al. (2005), Do satellites detect trends in surface solar radiation?, Science, 308(5723), 850-854, doi:10.1126/ science. 1103159.

Piomelli, U. (1999), Large eddy simulation: Achievements and challenges, Prog. Aerosp. Sci., 35, 335-362, doi:10.1016/ S0376-0421(98)00014-1.

Porté-Agel, F., et al. (2000), Subgrid-scale dissipation in the atmospheric surface layer: Effects of stability and filter dimension, J. Hydrometeorol., 1, 75-87, doi:10.1175/1525-7541(2000) $001<0075$ :SSDITA $>2.0 . \mathrm{CO} ; 2$

Porté-Agel, F., et al. (2001), A priori field study of the subgridscale heat fluxes and dissipation in the atmospheric surface layer, J. Atmos. Sci., 58(18), 2673-2698, doi:10.1175/1520-0469 (2001)058<2673:APFSOT $>2.0 . C O ; 2$.

Prentice, I. C., et al. (2011), Evidence of a universal scaling relationship for leaf $\mathrm{CO} 2$ drawdown along an aridity gradient, New Phytol., 190(1), 169-180, doi:10.1111/j.1469-8137.2010.03579.x.

Pryor, S. C., R. J. Barthelmie, D. T. Young, E. S. Takle, R. W. Arritt, D. Flory, W. J. Gutowski Jr., A. Nunes, and J. Roads (2009), Wind speed trends over the contiguous United States, J. Geophys. Res., 114, D14105, doi:10.1029/2008JD011416.

Ramanathan, V., et al. (2001), Aerosols, climate, and the hydrological cycle, Science, 294(5549), 2119-2124, doi:10.1126/ science. 1064034.

Raupach, M. R., and R. H. Shaw (1982), Averaging procedures for flow with vegetation canopies, Boundary Layer Meteorol., 22(1), 79-90, doi:10.1007/BF00128057.

Reid, C. D., et al. (2003), On the relationship between stomatal characters and atmospheric CO2, Geophys. Res. Lett., 30(19), 1983, doi:10.1029/2003GL017775.

Roberts, J. (1983), Forest transpiration: A conservative hydrologic process?, J. Hydrol., 66, 133-141, doi:10.1016/0022-1694(83) 90181-6.

Roderick, M. L., and G. D. Farquhar (2002), The cause of decreased pan evaporation over the past 50 years, Science, 298(5597), 1410-1411.

Roderick, M. L., et al. (2007), On the attribution of changing pan evaporation, Geophys. Res. Lett., 34, L17403, doi:10.1029/ 2007GL031166.

Rogers, R. F., and J. M. Fritsch (1996), A general framework for convective trigger functions, Mon. Weather Rev., 124(11), 2438-2452, doi:10.1175/1520-0493(1996)124<2438:AGFFCT > 2.0.CO;2.

Roy, S. B., and R. Avissar (2002), Impact of land use/land cover change on regional hydrometeorology in Amazonia, J. Geophys. Res., 107(D20), 8037, doi:10.1029/2000JD000266.

Santanello, J. A., et al. (2005), An empirical investigation of convective planetary boundary layer evolution and its relationship with the land surface, J. Appl. Meteorol., 44(6), 917-932, doi:10.1175/JAM2240.1.

Schäfer, K. V. R., et al. (2002), Hydrologic balance in an intact temperate forest ecosystem under ambient and elevated atmospheric CO2 concentration, Global Change Biol., 8(9), 895-911, doi:10.1046/j.1365-2486.2002.00513.x.

Schäfer, K. V. R., et al. (2003), Exposure to an enriched CO2 atmosphere alters carbon assimilation and allocation in a pine forest ecosystem, Global Change Biol., 9(10), 1378-1400, doi:10.1046/j.1365-2486.2003.00662.x.

Schlegel, F., et al. (2012), Large-Eddy Simulation of inhomogeneous canopy flows using high resolution terrestrial laser scanning data, Boundary Layer Meteorol., 142, 223-243, doi:10.1007/s10546-011-9678-1.

Scholz, F. G., et al. (2007), Biophysical properties and functional significance of stem water storage tissues in Neotropical savanna trees, Plant Cell Environ., 30(2), 236-248, doi:10.1111/j.13653040.2006.01623.x.

Sellers, P. J., et al. (1992), An overview of the 1st International Satellite Land Surface Climatology Project (ISLSCP) field experiment (FIFE), J. Geophys. Res., 97(D17), 18,345-18,371, doi:10.1029/92JD02111.

Sellers, P. J., et al. (1996), Comparison of radiative and physiological effects of doubled atmospheric CO2 on climate, Science, 271(5254), 1402-1406, doi:10.1126/science.271.5254.1402.

Sellers, P. J., et al. (1997), BOREAS in 1997: Experiment overview, scientific results, and future directions, J. Geophys. Res., 102(D24), 28,731-28,769, doi:10.1029/97JD03300.

Shaw, R. H., and U. Schumann (1992), Large-eddy simulation of turbulent flow above and within a forest, Boundary Layer Meteorol., 61, 47-64, doi:10.1007/BF02033994.

Sherwood, S. C., and C. L. Meyer (2006), The general circulation and robust relative humidity, J. Clim., 19(24), 6278-6290, doi:10.1175/JCLI3979.1

Shiklomanov, A. I. (1998), World Water Resources: A New Appraisal and Assessment for the Twenty-First Century: A Summary of the Monograph "World Water Resources" Report, 37 pp., UNESCO, Paris.

Siqueira, M. B., et al. (2006), Multi-scale model inter-comparison of $\mathrm{CO} 2$ and $\mathrm{H} 2 \mathrm{O}$ exchange rates above a maturing southeastern pine forest, Global Change Biol., 12, 1189-1207, doi:10.1111/ j.1365-2486.2006.01158.x.

Siqueira, M., et al. (2008), Onset of water stress, hysteresis in plant conductance, and hydraulic lift: Scaling soil water dynamics from millimeters to meters, Water Resour. Res., 44, W01432, doi:10.1029/2007WR006094.

Siqueira, M., et al. (2009), Soil moisture feedbacks on convection triggers: The role of soil-plant hydrodynamics, J. Hydrometeorol., 10(1), 96-112, doi:10.1175/2008JHM1027.1.

Skyllingstad, E. D., and D. Edson (2009), Large Eddy Simulation of moist convection during a cold air outbreak over the Gulf Stream, J. Atmos. Sci., 66, 1274-1293, doi:10.1175/2008JAS2755.1.

Smagorinsky, J. (1963), General circulation experiments with primitive equations, Mon. Weather Rev., 91, 99-164, doi:10.1175/ 1520-0493(1963)091<0099:GCEWTP>2.3.CO;2.

Sperry, J. S. (2000), Hydraulic constraints on plant gas exchange, Agric. For. Meteorol., 104(1), 13-23, doi:10.1016/S0168-1923 (00)00144-1.

Sperry, J. S., et al. (1998), Limitation of plant water use by rhizosphere and xylem conductance: Results from a model, Plant Cell Environ., 21, 347-359, doi:10.1046/j.1365-3040.1998.00287.x.

Stanhill, G., and S. Cohen (2001), Global dimming: A review of the evidence for a widespread and significant reduction in global radiation with discussion of its probable causes and possible agricultural consequences, Agric. For. Meteorol., 107(4), 255-278, doi:10.1016/S0168-1923(00)00241-0.

Stoy, P. C., et al. (2006), Separating the effects of climate and vegetation on evapotranspiration along a successional chronosequence in the southeastern US, Global Change Biol., 12(11), 2115-2135, doi:10.1111/j.1365-2486.2006.01244.x.

Tardieu, F., and W. J. Davies (1993), Integration of hydraulic and chemical signaling in the control of stomatal conductance and water status of droughted plants, Plant Cell Environ., 16, 341-349, doi:10.1111/j.1365-3040.1993.tb00880.x.

Trenberth, K. E., et al. (2007), Estimates of the global water budget and its annual cycle using observational and model data, J. Hydrometeorol., 8(4), 758-769, doi:10.1175/JHM600.1.

Tuzet, A., et al. (2003), A coupled model of stomatal conductance, photosynthesis and transpiration, Plant Cell Environ., 26(7), 1097-1116, doi:10.1046/j.1365-3040.2003.01035.x.

Tyree, M. T., and J. S. Sperry (1989), Vulnerability of xylem to cavitation and embolism, Annu. Rev. Plant Physiol. Plant Mol. Biol., 40, 19-36, doi:10.1146/annurev.pp.40.060189.000315. 
van den Honert, T. H. (1948), Water transport in plants as a catenary process, Discuss. Faraday Soc., 3, 146-153, doi:10.1039/ df9480300146.

Van Wylen, G. J., and R. E. Sonntag (1978), Fundamentals of Classical Thermodynamics, 2nd ed., 743 pp., John Wiley, New York.

Vecchi, G. A., et al. (2006), Weakening of tropical Pacific atmospheric circulation due to anthropogenic forcing, Nature, 441(7089), 73-76, doi:10.1038/nature04744.

Vercauteren, N., et al. (2009), Estimation of wet surface evaporation from sensible heat flux measurements, Water Resour. Res., 45, W06424, doi:10.1029/2008WR007544.

Vesala, T., et al. (2003), Refilling of a hydraulically isolated embolized xylem vessel: Model calculations, Ann. Bot., 91, 419-428, doi: $10.1093 / \mathrm{aob} / \mathrm{mcg} 022$.

Vico, G., and A. Porporato (2008), Modelling C3 and C4 photosynthesis under water-stressed conditions, Plant Soil, 313, 187-203, doi:10.1007/s11104-008-9691-4.

Volpe, V., et al. (2011), Leaf conductance and carbon gain under salt-stressed conditions, J. Geophys. Res., 116, G04035, doi:10.1029/2011JG001848.

Walter, M. T., et al. (2004), Increasing evapotranspiration from the conterminous United States, J. Hydrometeorol., 5(3), 405-408, doi:10.1175/1525-7541(2004)005<0405:IEFTCU>2.0.CO; 2 .

Wang, J. F., et al. (2000), The impact of observed deforestation on the mesoscale distribution of rainfall and clouds in Amazonia, $J$. Hydrometeorol., 1, 267-286, doi:10.1175/1525-7541(2000) $001<0267$ :TIOODO $>2.0 . \mathrm{CO} ; 2$.

Wang, J. F., et al. (2009), Impact of deforestation in the Amazon basin on cloud climatology, Proc. Natl. Acad. Sci. U. S. A., 106, 3670-3674, doi:10.1073/pnas.0810156106.

Warren, J. M., et al. (2011a), Elevated CO2 enhances leaf senescence during extreme drought in a temperate forest, Tree Physiol., 31(2), 117-130, doi:10.1093/treephys/tpr002.

Warren, J. M., et al. (2011b), Ecohydrologic impact of reduced stomatal conductance in forests exposed to elevated CO2, Ecohydrology, 4(2), 196-210, doi:10.1002/eco.173.

Wentz, F. J., et al. (2007), How much more rain will global warming bring?, Science, 317(5835), 233-235, doi:10.1126/science. 1140746.

Werth, D., and R. Avissar (2002), The local and global effects of Amazon deforestation, J. Geophys. Res., 107(D20), 8037, doi:10.1029/2000JD000266.
Wheeler, J. K., et al. (2005), Inter-vessel pitting and cavitation in woody Rosaceae and other vesselled plants: A basis for a safety versus efficiency trade-off in xylem transport, Plant Cell Environ., 28, 800-812, doi:10.1111/j.1365-3040.2005.01330.x.

Wheeler, T. D., and A. D. Stroock (2008), The transpiration of water at negative pressures in a synthetic tree, Nature, 455(7210), 208-212, doi:10.1038/nature07226.

Wilcox, B. P., and Y. Huang (2010), Woody plant encroachment paradox: Rivers rebound as degraded grasslands convert to woodlands, Geophys. Res. Lett., 37, L07402, doi:10.1029/ 2009GL041929.

Wild, M. (2009), Global dimming and brightening: A review, J. Geophys. Res., 114, D00D16, doi:10.1029/2008JD011470.

Wild, M., et al. (2005), From dimming to brightening: Decadal changes in solar radiation at Earth's surface, Science, 308(5723), 847-850, doi:10.1126/science.1103215.

Williams, M., et al. (1996), Modelling the soil-plant-atmosphere continuum in a Quercus-Acer stand at Harvard forest: The regulation of stomatal conductance by light, nitrogen and soil/plant hydraulic properties, Plant Cell Environ., 19, 911-927, doi:10.1111/j.1365-3040.1996.tb00456.x.

Wood, N. (2000), Wind flow over complex terrain: A historical perspective and the prospect for Large-Eddy Modelling, Boundary Layer Meteorol., 96, 11-32, doi:10.1023/A:1002017732694.

Woodward, F. I. (1990), Global change: Translating plant ecophysiological responses to ecosystems, Trends Ecol. Evol., 5(9), 308-311, doi:10.1016/0169-5347(90)90087-T

Wullschleger, S. D., and R. J. Norby (2001), Sap velocity and canopy transpiration in a sweetgum stand exposed to free-air CO2 enrichment (FACE), New Phytol., 150(2), 489-498, doi:10.1046/j.1469-8137.2001.00094.x.

Wullschleger, S. D., et al. (2002), Sensitivity of stomatal and canopy conductance to elevated $\mathrm{CO} 2$ concentration - Interacting variables and perspectives of scale, New Phytol., 153(3), 485-496, doi:10.1046/j.0028-646X.2001.00333.x.

Ziemer, R. R. (1979), Evaporation and transpiration, Rev. Geophys., 17(6), 1175-1186, doi:10.1029/RG017i006p01175.

Zwieniecki, M. A., and N. M. Holbrook (2009), Confronting Maxwell's demon: Biophysics of xylem embolism repair, Trends Plant Sci., 14, 530-534, doi:10.1016/j.tplants.2009.07.002. 